\title{
UNIVERSITY OF CAPE TOWN
}

Faculty of Science

Department of Oceanography

A minor thesis submitted in partial fulfillment for the degree of MSc Ocean and Climate Dynamics

Supervisor: Dr. Julie Deshayes, Dr. Bjorn Backeberg, Dr. Ben Loveday, Dr. Juliet Hermes and Prof. Chris Reason

Spatio-Temporal Characteristics of the Agulhas Leakage: a model inter-comparison study

by Lisa E. Holton

April 7, 2015 
The copyright of this thesis vests in the author. No quotation from it or information derived from it is to be published without full acknowledgement of the source. The thesis is to be used for private study or noncommercial research purposes only.

Published by the University of Cape Town (UCT) in terms of the non-exclusive license granted to UCT by the author. 



\section{UNIVERSITY OF CAPE TOWN}

\section{$\underline{\text { ABSTRACT }}$ \\ FACULTY OF SCIENCE \\ DEPARTMENT OF OCEANOGRAPHY}

A thesis submitted in partial fulfillment for the degree of MSc Ocean and Climate dynamics

by Lisa E. Holton

Investigating the variability of the Agulhas leakage, the volume transport of water from the Indian Ocean to the South Atlantic Ocean, is highly relevant due to its potential contribution to the Atlantic Meridional Overturning Circulation (AMOC) and the global circulation of heat, salt and freshwater, hence to the global climate. As observations of the leakage are scattered in time and space, ocean model outputs are unavoidable to describe its mechanisms of variability. However, the Agulhas leakage is part of a system that still represents a challenge to modellers, because of its degree of non-linearity. As a consequence, this thesis reports the study of the mechanisms of variability of the Agulhas leakage in six ocean model outputs of varying resolution, vertical discretization and boundary conditions. Inter-comparing several model outputs allow one to identify which characteristics of variability are robust. It also provides valuable information on the model specifics required to correctly represent the mechanisms of variability of the Agulhas leakage and hence its contribution to climate variability.

The Agulhas leakage is estimated at the Good Hope line, a section through the centre of the Cape Basin, using a Eulerian threshold integration method based on the thermohaline properties of water masses along the line. The threshold method also takes into account the thermohaline biases of each model. Other methods have been tested but the former was selected because it yields an Agulhas Leakage that represents $60 \%$ of the actual magnitude as determined by a passive tracer method (only available in one simulation) and captures nearly all of the temporal variability.

One result common to all simulations is the lack of seasonality in the Agulhas leakage, its intensity is regulated by changes in depth rather than by variations in the offshore 
extent. The fluctuations on the seasonal timescale reflect the meridional migrations of isotherms and isohalines. The major driver of variability in the leakage comes from the passing of mesoscale features through the Good Hope line. It is important to note that in the absence of those, the leakage does not vanish, suggesting that there is a non-zero background leakage, although its intensity is very sensitive to the choice of threshold in the estimation method. Hindcast models of high resolution $\left(1 / 12^{\circ}\right)$ agree on the temporal (3-4 rings per year) and spatial $(300-500 \mathrm{~km})$ scales of the mesoscale features influencing the leakage, and those correspond to the observed Agulhas rings, even though the models diverge substantially in the pathways of rings. Coarser resolution models $\left(1 / 4^{\circ}\right)$ are able to reproduce similar time scales of variability for the leakage, but the spatial characteristics (pathways and wavelength) of the mesoscale features are different. For one model, they are close to Rossby waves at this latitude, which justifies the continued effort to produce high resolution hindcasts for the Agulhas region. Finally, the coarser resolution climate model that was investigated does not resolve the mechanism of variability of the Agulhas leakage as produced by the higher resolution hindcasts, which suggests that the impact of the Agulhas Current system on climate is not realistic in this model. With increasing interest in the future stability of the large scale ocean circulation, climate models need to include ocean models of increased spatial resolution to realistically produce the mechanisms of variability of the Agulhas leakage. 


\section{Contents}

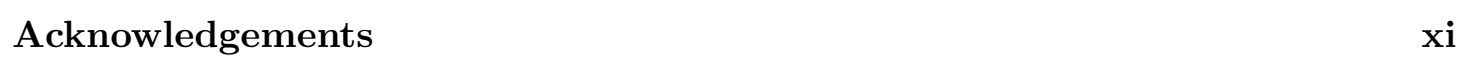

$\begin{array}{lll}1 & \text { Introduction } & 1\end{array}$

2 Literature Review 5

$2.1 \quad$ Regional Context . . . . . . . . . . . . . . . . . . . . . 5

2.2 Components of Regional Circulation $\ldots \ldots \ldots \ldots$. . . . . . . . . . . . . . . . . . . 6

2.3 Quantification of the AD . . . . . . . . . . . . . . . . . . . 12

$2.3 .1 \quad$ Eulerian . . . . . . . . . . . . . . . . . . . . . . . 12

2.3 .2 Lagrangian . . . . . . . . . . . . . . . . . . . . . . . . . . . . . . . . . . . . 14

2.4 Conclusion $\ldots \ldots \ldots \ldots \ldots \ldots \ldots$

\begin{tabular}{lll}
\hline 3 & Methods & 17
\end{tabular}

3.1 Model Outputs $\ldots \ldots \ldots \ldots \ldots \ldots$. . . . . . . . . . . . . . . . . . . . . . . . . . . . . . .

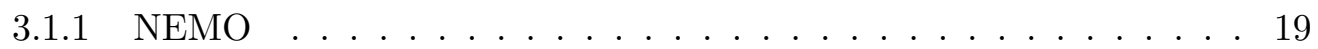

3.1 .2 HYCOM $\ldots \ldots \ldots \ldots \ldots$

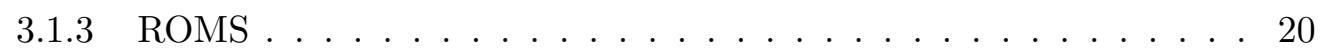

3.1 .4 PAGO Extraction . . . . . . . . . . . . . . . . . . . . . . . . . . . 20

3.2 Quantifying the Agulhas Leakage . . . . . . . . . . . . . . . . . . . . . . 21

$3.2 .1 \quad$ Van Sebille Thresholds . . . . . . . . . . . . . . . . . . . . . 22

3.2 .2 Validation of Threshold Methods . . . . . . . . . . . . . . . . 23

3.2 .3 AC1 Line . . . . . . . . . . . . . . . . . . . . . . . . . . . . . . . . . . . . . 24

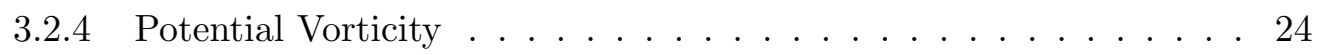

3.2 .5 Including Bias . . . . . . . . . . . . . . . . . . . . . . . . . . . . . . . . . . . . . . . . . . .

3.3 Barotropic Streamfunction . . . . . . . . . . . . . . . . . 27

3.4 Spectral Analysis . . . . . . . . . . . . . . . . . . . . . . . . . 28

3.5 Final Method . . . . . . . . . . . . . . . . . . . . . . . . . . 28

\begin{tabular}{|ll|r}
\hline 4 & Results & 31
\end{tabular}

$4.1 \quad$ Validation of High Resolution Hindcasts . . . . . . . . . . . . . . . . . . . . . . 31

4.1 .1 Thermohaline Structure Along the GH Line . . . . . . . . . . . . . . . . . . 31

4.1 .2 Mean circulation through the GH line . . . . . . . . . . . . . . 35

4.1 .3 Anomalies in Thermohaline Structure Along the GH Line . . . . . 36

4.1 .4 Mean Agulhas Leakage Volume Transport . . . . . . . . . . . . . . 39

4.2 Spatial Variability of The Agulhas Leakage . . . . . . . . . . . . . . . . . . . 40

4.3 Temporal Variability of the Agulhas Leakage . . . . . . . . . . . . . . . . . . . . . . . . 44

4.3 .1 Seasonality . . . . . . . . . . . . . . . . . . . . 44

4.3 .2 Interannual Variability . . . . . . . . . . . . . . . . . . . 46 
4.4 Effect of Model Resolution . . . . . . . . . . . . . . . . . . . . . . . . . 48

4.4 .1 Temporal Variability $\ldots \ldots \ldots \ldots$

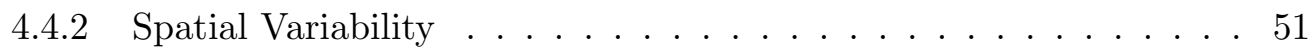

4.5 Summary . . . . . . . . . . . . . . . . . . . . . . . . 52

$\begin{array}{lll}5 & \text { Conclusions } & 55\end{array}$

$\begin{array}{lll}6 & \text { Bibliography } & 61\end{array}$ 


\section{List of Figures}

1.1 A map of the average AVISO eddy kinetic energy (EKE) from 19922007 south of Africa. The region of high EKE corresponds to the Agulhas Retroflection and associated mesoscale activity. Agulhas Rings are spawned from the retroflection and act as vehicles transporting warm, salty water from the Indian Ocean to the South Atlantic. The black arrows represent the path of the Agulhas Current along the coast of South Africa before it retroflects back towards the Indian Ocean. The GoodHope Line is overlaid in black. . . . . . . . . . . . . . . . . . 2

2.1 Schematic of the large scale dynamics that make quantifying the AL very complex, overlaid on the bathymetry $(\mathrm{m})$ of the Agulhas region. Bold or dashed lines represent the observational lines. As equation 2.1 demands $\mathrm{T}_{A L}$ is the $\mathrm{AL}, \mathrm{T}_{A C}$ is the transport held within the $\mathrm{AC}, \mathrm{T}_{A R C}$ is the transport associated with the Agulhas Return Current and $\mathrm{T}_{R}$ is the remainder transport which never leaves the domain. Letters detail the main bathymetric features referred to in the text: (A) the Walvis Ridge, \begin{tabular}{ll|l} 
(B) the Cape Basin, (C) the Agulhas Ridge and (D) the Erica Seamount. & 6
\end{tabular}

2.2 Schematic of the three eddy routes guided by bathymetry through the Cape Basin as proposed by and adapted from Dencausse et al., 2010b . . 9

3.1 The full GH line and zoom of the stepwise PAGO stair-case extraction steps for ORCA025 (left) and ORCA12 (right). The size of the staircase depends on the grid resolution, with sections following the shortest great circle between end points. The resulting section velocities depend on the orientation of the current to the $\mathrm{u}, \mathrm{v}$ faces. A current orientated in the direction of the blue arrow will display both negative and positive values resulting in velocity stripes, but only positive values if orientated in the direction of the red arrow . . . . . . . . . . . . . . . . . . 21

3.2 Time series comparison between the Agulhas leakage transport estimated using the Eulerian integration method proposed in this study for the ARC112i output (red line) and the transport from an Eulerian passive tracer method for ARC112i (black line) calculated by Loveday et al. [2014] for $1970-1990 . \ldots \ldots \ldots \ldots \ldots \ldots$

4.1 Observed temperature $\left({ }^{\circ} \mathrm{C}\right)$ and salinity (PSU) profiles from the 2008 BONUS-GOODHOPE cruise. The section is only a snapshot in time so cannot be used to identify temporal variability, however it is representative of how the water masses are positioned in the offshore direction and with depth. The major water masses are labelled in the salinity section: Antarctic Intermediate Water (AAIW), North Atlantic Deep Water (NADW) and Antarctic Bottom Water (AABW). . . . . . . . . . . 32 
4.2 Temperature (left), salinity (middle) and normal velocity (right) in ORCA12 (top), AGUa0.10 (middle) and ARC112i (bottom). The overlaid black line represents the bias adjusted van Sebille thresholds for temperature and salinity and combined mask for velocity. . . . . . . . . . . . . . 33

4.3 Temperature vs. salinity profiles for the Good Hope 2008 observations (green), ORCA12 (black), AGUa0.10 (blue) and ARC112i (red). Each temperature and salinity profile is taken at 500km offshore. . . . . . . . 34

4.4 The barotropic stream function (equation 3.4 for ORCA12 (in Sv). Red lines indicate cyclonic circulation and blue lines anticyclonic circulation, the thin black line represents the zero contour. The GH line is overlaid in black. The location of a bathymetric feature 500km offshore is circled. $\quad 36$

4.5 Snapshots of temperature salinity and normal velocity at time steps when the AL is maximum: in July 1996 for ORCA12 (top), in March 2004 for AGUa0.10 (middle) and in February 1962 for ARC112i (bottom). Black lines as in Figure 4.2 at the corresponding time steps. . . . . . . . . . 37

4.6 Snapshots of sea surface height (SSH) for the same time periods as Figure 4.5 for ORCA12 (top), AGUo0.10 (middle) and ARC112i (bottom). . . . 38

4.7 ORCA12 (top), AGUa0.10 (middle), ARC112i (bottom) spatial spectra of velocity across GH line. Grey lines represent spectra for each time step and the thick black line is the average of all spectras. In the top panel the dotted line represents sprectras preformed on a meriodional straight line across the Cape Basin and the dashed a zonal line. . . . . . . . . . . 42

4.8 Time series and Hovmoller plot of cumulated transport from the coast offshore of the AL. The common time period from 1994-2008 has been chosen for comparison. Top: ORCA12, right: AGUa0.10, bottom: ARC112i 43

4.9 ORCA12, AGUa0.10, ARC112i normalised seasonal cycle of total, net, area and offshore extent. The highest correlation between cycles occurs for area and total transports by $0.89,0.46$ and 0.80 for ORCA12, AGUa0.10

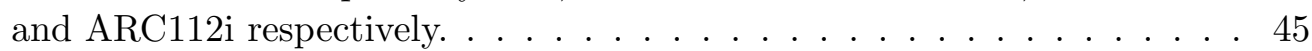

4.10 Time spectral analysis of the net (top) and total (bottom) transports for the three model outputs (ORCA12 is the black line, AGUa0.10 is the blue line and ARC112i the red line). The change in slope identifies the dominant time scale of variability. . . . . . . . . . . . . 47

4.11 Spectral analysis of the net (left) and total (right) transports for top: AGUa0.10 (black) and INDa0.12 (blue), middle: ORCA12 (black) and ORCA025 (blue), bottom: IPSL-CM5. The dominant change in slope identifies the dominant time scale of variability $\ldots \ldots \ldots$. . . . . . . 50

4.12 Same as Figure 4.7 for ORCA025 (top) and INDa0.12 (bottom). . . . . . 51

4.13 Same as Figure 4.8 for ORCA025 . . . . . . . . . . . . . . . . 52 


\section{List of Tables}

2.1 AL estimates from varying Eulerian and Lagrangian methods. . . . . . . . 8

3.1 Specificities of model simulations diagnosed. Z level in the upper ocean mixed layer, isopycnic $(\rho)$ vertical coordinates in the stratified open ocean and sigma $(\sigma)$ coordinates in shallow coastal regions. $\ldots \ldots \ldots . \ldots 18$

$3.2 \quad$ The calculated mean temperature and salinity values taken from the mean surface layer from the coast to $500 \mathrm{~km}$ offshore. The bias' are then calculated as the difference from those of ARC112i. The temperature and salinity thresholds are then adjusted using these bias from those of van Sebille $\left.\left(\mathrm{T}=14.6^{\circ} \mathrm{C} \mathrm{S}=35.3\right)\right] \ldots \ldots \ldots \ldots \ldots 26 \ldots \ldots \ldots \ldots$

4.1 Model estimates of AL using the adjusted thresholds from van Sebille including bias from Table $3.2 \ldots \ldots . \ldots . \ldots . \ldots 39$

4.2 Ratios of variance of [i] seasonal cycle and [ii] anomalies from the seasonal cycle, over the total variance of NET and TOTAL AL transport, for each model (in \%) with the standard deviation for the full time series (in Sv). . 46

4.3 Coarse resolution model estimates of AL using the adjusted thresholds from van Sebille (Table 3.20 . . . . . . . . . . . . . . . . . . 48 48

4.4 Comparison of the major results of each model to those of observations from the literature. The high resolution hindcasts represent the spatial and temporal variability well, however they differ from observation in the route of the dominant ring pathways. . . . . . . . . . . . . . 53 



\section{Acknowledgements}

I would like to say a huge merci beaucoup to Dr. Julie Deshayes as her dedication, enthusiasm and knowledge has helped guide and shape this thesis and kept the spirit of exploration throughout. Thanks also to Julie for the PAGO extractions and the DRAKKAR group for the NEMO outputs. A huge thank you to Dr. Bjorn Backeberg and Dr. Ben Loveday for their helpful comments and for providing their HYCOM and ROMS model outputs. I would also like to acknowledge the UCT department, Prof. Chris Reason and Dr. Juliet Hermes from SAEON for continued guidance and for the funding of this project. Finally, many thanks to Claude Talandier (CNRS, LPO) and Juliette Mignot (IRD, LOCEAN) for making the outputs of ORCA025 and IPSL-CM5 simulations available.

The financial assistance of the South African Environmental Observation Network (SAEON) towards this research is acknowledged. Opinions expressed and conclusions arrived at are those of the author and are not necessarily to be attributed to SAEON.

I know the meaning of plagarism and declare that all of the work in the document, save for that which is properly acknowledged, is my own. 



\section{Chapter 1}

\section{Introduction}

The Agulhas leakage (AL), as defined by the transport of water masses from the Indian Ocean to the South Atlantic Ocean, plays a crucial role in the global circulation of heat and freshwater in the current climate, through and beyond its impact on the Atlantic Meridional Overturning Circulation (AMOC). The AL is thought to be primarily rendered by Agulhas rings [Figure 1.1], formed from the retroflection of the Agulhas Current at a rate of 5-6 per year [Schouten et al., 2002]. Fronts and submesoscale features in between rings also contribute to the net westward transport of water masses at the southern tip of Africa. Hence, to realistically resolve the AL it is assumed that numerical models require high spatial resolution. State-of-the-art high-resolution ocean hindcasts are now able to reproduce the turbulent processes of the Agulhas Current realistically [Loveday et al., 2014; Backeberg et al., 2012, 2014]. However, how well these simulations compare with each other with regard to the AL has not yet been investigated. In order to achieve such an inter-comparison of the AL over several ocean models a robust method is required that can estimate the associated transport of volume, independent of the differences in model setup.

The dynamics of the AL is complex because of the turbulent nature of the Cape Basin (region south west of the southern tip of South Africa), which also makes direct measurements difficult. Leakage estimates are thus highly variable, ranging from 10-41 Sv [1 


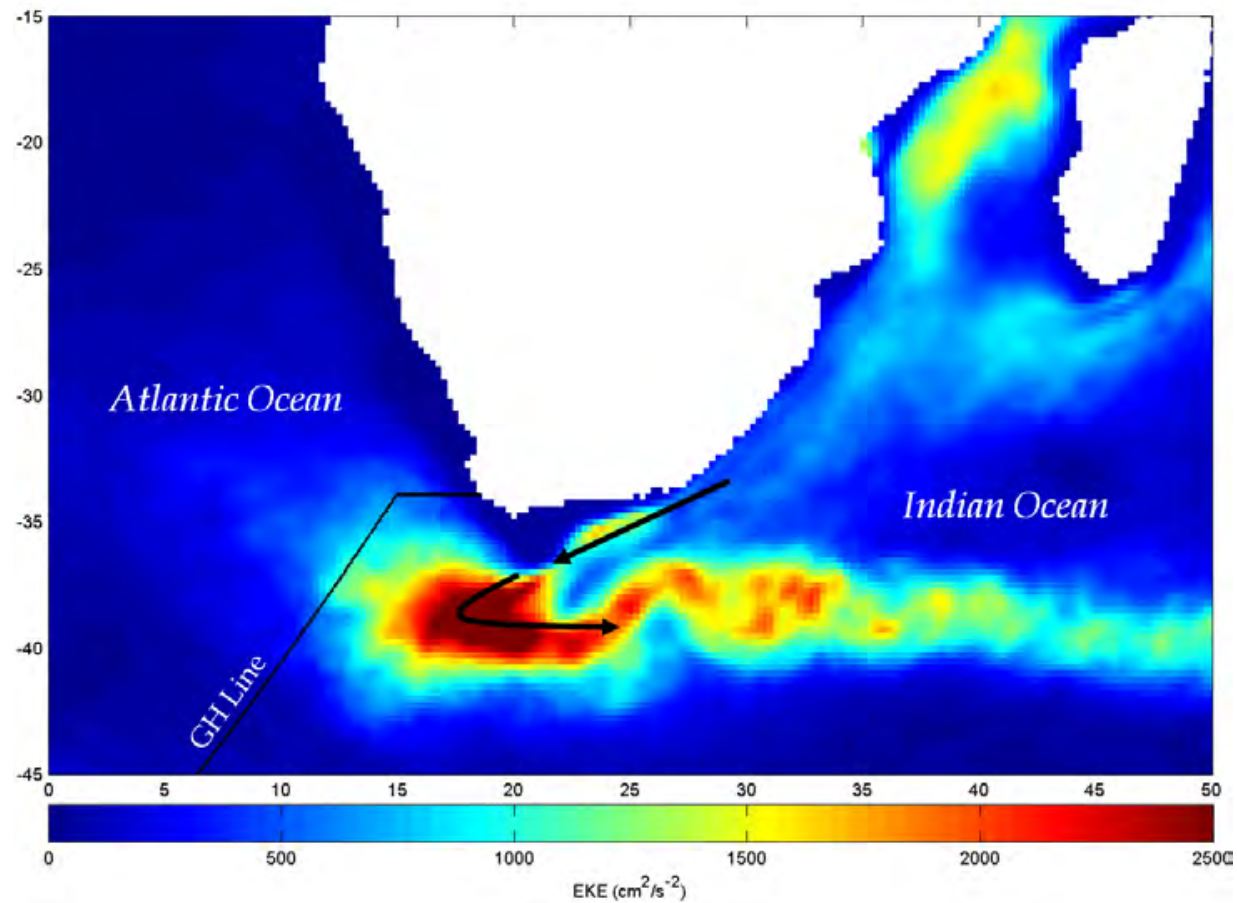

Figure 1.1: A map of the average AVISO eddy kinetic energy (EKE) from 1992-2007 south of Africa. The region of high EKE corresponds to the Agulhas Retroflection and associated mesoscale activity. Agulhas Rings are spawned from the retroflection and act as vehicles transporting warm, salty water from the Indian Ocean to the South Atlantic. The black arrows represent the path of the Agulhas Current along the coast of South Africa before it retroflects back towards the Indian Ocean. The GoodHope Line is overlaid in black.

$\mathrm{Sv}=10^{6} \mathrm{~m}^{3} \mathrm{~s}^{-1}$ ] [Gordon et al., 1987; Speich et al., 2001; van Sebille et al., 2013]. The observational GoodHope line (GH), used in the above estimates and in the present study, follows the TOPEX/POSEIDON-JASON 1 satellite ground track [Ansorge et al., 2005]. It is positioned in the Cape Basin north west of the Agulhas Current retroflection and acts as a transitional boundary between the South Atlantic and Indian oceans [Figure 1.1]. The most simple Eulerian approach assumes that the waters of Indian Ocean origin represent the warmest and most saline waters across the Good Hope section. These thermohaline properties can then be utilised in order to establish an integration domain over which volume transport is calculated. The limitation of such an approach is that by imposing water mass criteria, the leakage in eddy-rich regions may be underestimated, although similar methods have been shown to reproduce the variability well [van Sebille et al., 2009; Loveday et al., 2014]. Another method is to use a Lagrangian approach in which numerical floats are released into the eastern Agulhas Current domain, and after a 
certain time period the amount of floats that have crossed a certain section to the west of the retroflection defines the volume transport of the leakage. Although this method has been seen to estimate the magnitude of the leakage well it is computationally expensive and does not resolve the submesoscale processes.

Because the Agulhas Retroflection is highly nonlinear, we expect a large variety of mean estimates for the leakage. Despite the significant model differences, the processes of variability of the leakage should be comparable among simulations. Also, as it is the variability of the AL that plays a major role in gauging northern Atlantic Ocean climate fluctuations rather than the mean magnitude [van Sebille et al., 2009], it is of greater importance to understand the dominant mechanisms of variability. The AL varies both in time and space which complicates measurements. The variability of the leakage is expected to be forced predominately by variability in the Agulhas Current, with the dynamics of the wind driven Agulhas system seen to mediate the magnitude of leakage in past studies [de Ruijter et al., 1999; van Sebille et al., 2009]. Any seasonality of the Agulhas Current would then be expected to be seen in the AL. However, variability in the South Atlantic and Southern Ocean may also influence the leakage.

Here, the variety of ocean hindcasts produced at the University of Cape Town and within the DRAKKAR project will be used to explore the sensitivity of the AL to model configuration, by comparing the characteristics of variability in three models of comparable high resolution $\left(1 / 12^{\circ}\right)$. As current state-of-the-art climate models, contributing to CMIP5 intercomparison project, have low spatial resolution (of the order of $1^{\circ}$ ) which is insufficient to reproduce Agulas rings, one would not expect the AL to be correctly represented in these models. However, the coarse resolution climate models are able to reproduce a form of leakage, in the absence of rings, that transports mass, heat and freshwater/salt from the Indian Ocean to the Atlantic Ocean. Here we additionally analyse two $1 / 4^{\circ}$ simulations and one $2^{\circ}$ climate simulation to compare the characteristics of variability in the volume transports to those of the high resolution hindcasts. This should be considered a first step to verify whether coarser resolution ocean models and 
hence climate models are able to reproduce the correct processes of variability of the AL.

A comprehensive literature review on the AL is presented in the next chapter. By means of an in depth description of the Agulhas Current system, we show how complex the dynamics are and hence the difficulty in measuring the leakage. This is followed by a critical review of the methodology used in past estimates of the AL, split into the two main methods, Eulerian and Lagrangian. Finally, a conclusion about which type of method is most appropriate for this study is discussed. Chapter 3 includes details of the models used as well as the full methodology undertaken within this study. In Chapter 4, the major results of the inter-comparison of the hindcast models are presented, followed by a comparison with coarse resolution models. Chapter 5 presents a synthesis and discussion of results. 


\section{Chapter 2}

\section{Literature Review}

\subsection{Regional Context}

The AL is defined as the transport of water masses from the Indian Ocean to the South Atlantic Ocean. The inter-ocean exchange of heat and salt around South Africa is potentially one of the most important agents in the maintenance of the global overturning circulation in the ocean [Biastoch et al., 2008a] and hence global climate [Gordon, 1985]. On a global level, the Agulhas region is at the cross roads of three circulation systems: the Antarctic Circumpolar Current (ACC) and the South Atlantic and South Indian Ocean subtropical gyres [van Sebille et al., 2009a]. The magnitude of the AL is thus sensitive to changes in all three systems and quantification is complex, as the relatively small AL flux is difficult to distinguish from those of the large circulation systems. Observational estimates of AL are limited, therefore most existing estimates are based on the outputs of numerical models.

Indian Ocean water is warmer and saltier than South Atlantic waters. Various geostrophic velocities derived from past meridional hydrographic sections (SAVE, SR2 and AJAX) located near $10^{\circ} \mathrm{E}$ in the Southern Ocean, south of Africa, confirm a westward flow of Indian Ocean waters into the Atlantic in the upper 1000m [Gordon et al., 1992; Mercier 
et al., 2003; Whitworth and Nowlin, 1987]. This is also shown by the pattern of float velocities from numerical and observational Lagrangian methods [Richardson et al., 2007]. However estimates of the AL are difficult due to the complexity of currents around South Africa [Richardson et al., 2003]. The area south west of the African continent, is named the Cape Basin. The bathymetry of the Cape Basin is complex, with a flat plain bordered by ridges with significant seamounts in the central region [Figure 2.1]. Flows here are far from laminar due to topographic steering and the convergence of large circulatory systems, such as the Agulhas Current and the South Atlantic Current. Due to the turbulent nature and vigorous mixing in the Cape Basin, the magnitude of the $\mathrm{AL}$ is difficult to quantify.

\subsection{Components of Regional Circulation}

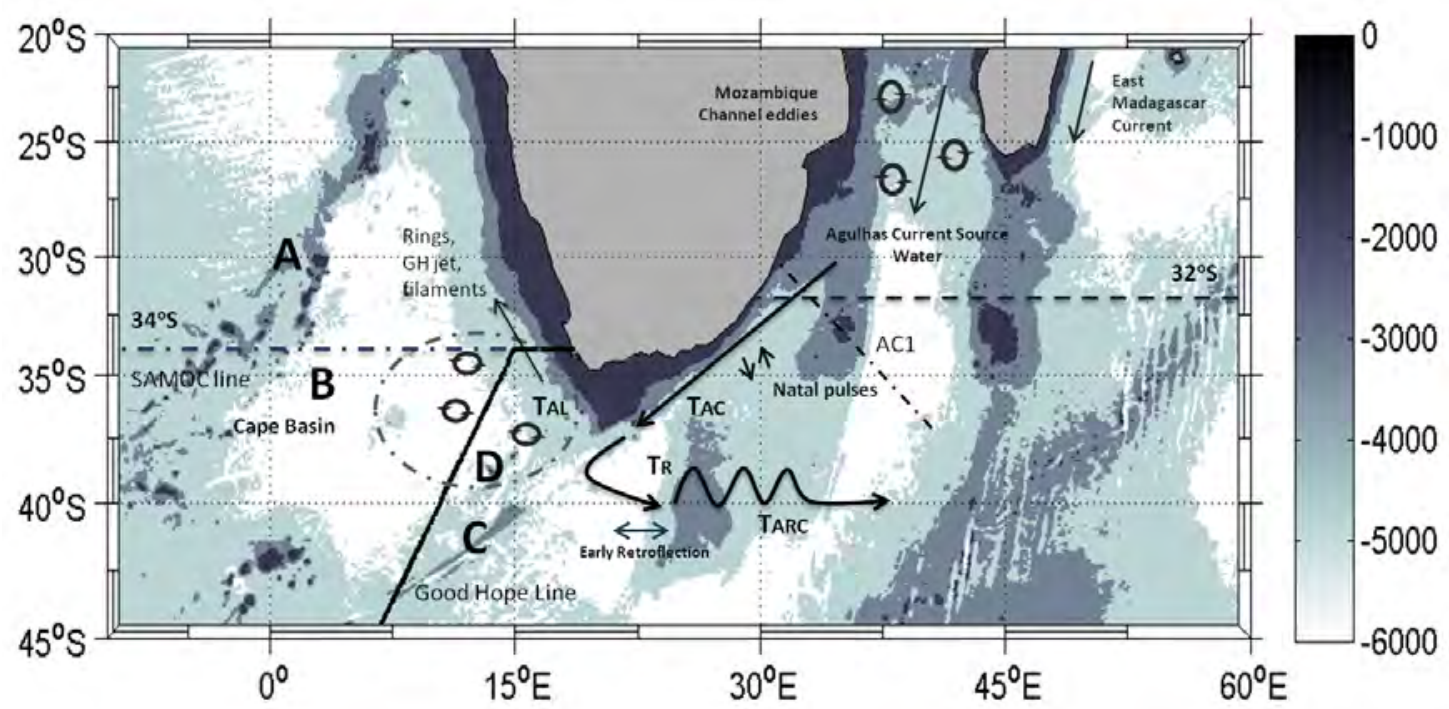

Figure 2.1: Schematic of the large scale dynamics that make quantifying the AL very complex, overlaid on the bathymetry $(\mathrm{m})$ of the Agulhas region. Bold or dashed lines represent the observational lines. As equation 2.1 demands $\mathrm{T}_{A L}$ is the $\mathrm{AL}, \mathrm{T}_{A C}$ is the transport held within the $\mathrm{AC}, \mathrm{T}_{A R C}$ is the transport associated with the Agulhas Return Current and $\mathrm{T}_{R}$ is the remainder transport which never leaves the domain. Letters detail the main bathymetric features referred to in the text: (A) the Walvis

Ridge, (B) the Cape Basin, (C) the Agulhas Ridge and (D) the Erica Seamount.

The AL is the result of a complex, highly non-linear interaction between the Agulhas Current (AC), the mesoscale variability of its source region and the regions south west of Africa where the bulk of the current retroflects back towards the Indian Ocean as 
the Agulhas Return Current (ARC). The AC is the western boundary current of the South Indian Ocean subtropical gyre and carries a mean transport of $70 \mathrm{~Sv}$ at $32^{\circ} \mathrm{S}$ [Bryden et al., 2005a]. The main driver of mesoscale variability in the northern AC is that of Natal pulses, these meanders form approximately 6 times a year and propagate south westward along the coast at 10km/day [Lutjeharms et al., 2003]. In the southern AC, variability is independent of Natal Pulses due to the separation of the continental shelf from the coast (Agulhas Bank). East of the Agulhas bank, the AC detaches from the continent, forming a free jet which retroflects to conserve its potential vorticity [de Ruijter et al., 1999]. The AC is not the only current to retroflect (Brazil, North Brazil and East Australia Current also have retroflections) but it is the only current to do so in the open ocean. As the retroflection connects the $\mathrm{AC}$ with the $\mathrm{ARC}$, there would be no $\mathrm{AL}$ if all transport of the $\mathrm{AC}$ flowed into the $\mathrm{ARC}$. As a result, the AL represents the proportion of the $\mathrm{AC}$ waters lost to the Atlantic as the current retroflects. The retroflection is highly variable and dynamically complex. Its position and strength are controlled by, but are not limited to, the amount of inertia of the Agulhas Current, slope of isopycnals, curvature of coast line, bathymetry and the wind stress curl [De Ruijter et al., 1999]. The variability in retroflection and hence leakage ranges between two extremes: when the retroflection occurs east of the Agulhas Plateau (deemed early retroflection), the AL is decreased and sometimes negligible [Speich et al., 2006]. On the contrary, if the retroflection is strong, to the west, and thus more unstable, the AL is increased [Figure 2.1].

The AL is forced by the AC which itself is forced by wind stress curl over the South Indian Ocean, hence the majority of variability in the AL would be expected to be driven by that in the AC. However as at least part of the AL is linked to the AMOC, variability is not expected to be solely associated to the AC and wind stress curl. High seasonal variability linked to the monsoon system and inter-annual variability due to El Nino Southern Oscillation [Reason et al., 2010] and the Indian Ocean dipole is also expected to be expressed in the AC. Hermes et al. [2007] showed that AC strength varies on an intra-annual basis (with transport maxima in Austral spring), however so far no study 
on the seasonal variability of the magnitude of the AL has been carried out [van Sebille et al., 2009]. The AL is not a constant flow, instead it is intermittent and governed by mesoscale and sub-mesoscale processes. Mean estimates vary from 10-41 Sv, with most falling in the range of 10-20 Sv with large uncertainty [Table 2.1]. In coarse resolution non eddy permitting models, the AL is seen as a continuous flow from the Indian to Atlantic ocean, and a much higher fraction of the Agulhas waters enters the Atlantic [Dykstra and de Ruijter, 2001]. On the other hand, in high resolution eddy permitting models, the AL is represented by a stream of large coherent eddies (Agulhas rings) shed from the retroflection. In the real ocean, the latter is only partially true as the retroflection is not a steady system, its position varies in time with instabilities in the $\mathrm{AC}$ resulting in the formation of large anticyclonic Agulhas rings which can move into the Atlantic (detectable from satellite temperature and SSH). Unlike in models, rings in the real ocean have defined pathways and ring shedding is highly variable, making shedding events difficult to model realistically [Dencausse et al., 2010].

TABLE 2.1: AL estimates from varying Eulerian and Lagrangian methods.

\begin{tabular}{|c|c|c|}
\hline Author & Method & AL transport \\
\hline \multicolumn{3}{|l|}{ Eulerian } \\
\hline Gordon (1986) & NADW formation & $14 \mathrm{~Sv}$ \\
\hline Gordon et al. (1987) & Hydrography & $10 \mathrm{~Sv}$ \\
\hline Ganachaud and Wunsch (2000) & Inverse Modelling & $17 \mathrm{~Sv}$ \\
\hline Garzoli and Goni (2000) & AVISO SSH altimetry & $17 \mathrm{~Sv}$ \\
\hline Boebel et al. (2003a) & Float trajectories & $10 \mathrm{~Sv}$ \\
\hline Treguier et al. (2003) & Model fluxes & $11 \mathrm{~Sv}$ \\
\hline Van Sebille et al. (2009b) & AVISO SSH altimetry & $13.2 \pm 1.5 \mathrm{~Sv}$ \\
\hline Van Sebille et al. (2010a) & T/S thresholds & $12.5 \mathrm{~Sv}$ \\
\hline Loveday et al. (2014) & Passive tracer flux & $18.8 \mathrm{~Sv}$ \\
\hline \multicolumn{3}{|l|}{ Lagrangian } \\
\hline Speich et al. (2001) & Numerical floats & $13.9 \mathrm{~Sv}$ \\
\hline Donners and Drijfhout (2004) & Numerical floats & $15.2 \mathrm{~Sv}$ \\
\hline Speich et al. (2006) & Numerical floats & $41 \mathrm{~Sv}$ \\
\hline Doglioli et al. (2006) & Numerical floats & $14 \mathrm{~Sv}$ \\
\hline Richardson (2007) & Observations & $15 \mathrm{~Sv}$ \\
\hline Van Sebille et al. (2010a) & Numerical floats & $16.7 \mathrm{~Sv}$ \\
\hline Durgadoo et al. (2013) & Numerical floats & $16.6 \pm 1.7 \mathrm{~Sv}$ \\
\hline Ruhs et al. (2013) & Numerical floats & $15.3 \mathrm{~Sv}$ \\
\hline Loveday et al. (2014) & Numerical floats & $18.9 \mathrm{~Sv}$ \\
\hline
\end{tabular}


As Agulhas rings have been well observed, rather than trying to identify the complete AL, Agulhas rings have predominately been used as a proxy for the AL [de Ruijter, 2006; Dencausse et al., 2011; Souza et al., 2011; Beronvera et al., 2013]. Agulhas rings from in-situ measurements and altimetry are seen as large coherent structures with an average radius of $150-200 \mathrm{~km}$ and surface velocities which exceed $1 \mathrm{~m} / \mathrm{s}$. These values are reported in the literature however, currently observational measurements are restricted by relatively large horizontal resolutions which may mean that smaller rings are not sampled correctly. Rings are shed on average every 2-3 months at a rate of 5-6 per year, however there can be sustained periods with no rings produced which are not reproduced in numerical models [Schouten et al., 2000; Van Aken et al., 2003; Doglioli et al., 2007]. Rings are not easily measured, as turbulence in the Cape Basin leads to the decay of rings (cyclones in particular decay quickly). Also topographic steering in the Cape Basin leads to three routes [Figure 2.2] for Agulhas rings - north-east of the Erica seamount [Figure 2.1], central passing between the Agulhas Ridge and the pre-mentioned seamount and a southern route [Dencausse et al., 2010b].

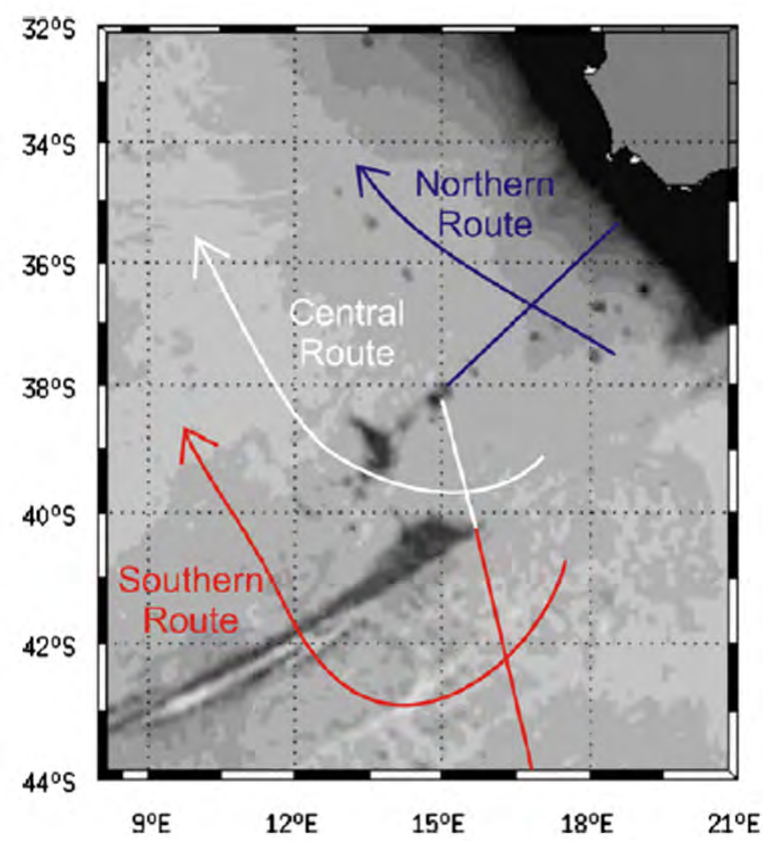

Figure 2.2: Schematic of the three eddy routes guided by bathymetry through the Cape Basin as proposed by and adapted from Dencausse et al., 2010b

After 5 months, the majority of rings have reduced by $40 \%$ with the majority of decay occurring through air-sea interaction and lateral intrusions from surrounding water 
masses [de Ruijter, 2006]. Agulhas rings are able to move large volumes of Indian Ocean water (water properties are determined by the duration and period of year the structures spend in the formation region [Dencausse et al., 2010b]) into the Atlantic ocean, as one ring is estimated to carry a surface volume transport of 0.5-1.5 Sv [Schouten et al, 2000]. It is very difficult to estimate the subsurface structure and therefore the total water mass transport of rings, however from surface expressions with only 5-6 rings per year, rings cannot be the only vehicle of exchange as alone they cannot produce the estimated 15 Sv of transport. The extra contribution to Indian-Atlantic exchange is likely provided through sub-mesoscale processes including filaments and jets [Lutjeharms 1996].

Filaments are on average 50km wide and 50m deep and carry heat and salt anomalies and are present about $56 \%$ of the time [Lutjeharms 1996]. Similar to Agulhas rings this heat anomaly is quickly lost, leaving the salt flux as the major addition to the exchange. The contribution of such features is thought to be small (15\% of AL [Lutjeharms 1996]), and in literature it is the least studied component of the AL. However, with the evolution of hydrodynamic models reaching very high horizontal resolution, the importance of the sub-mesoscale in inter-ocean exchange is becoming a highly prevalent topic. The least understood structure is that of a background mean flow. A mean flow has the potential to exchange waters more directly into the Benguela Current and thus participate in the AMOC [Donners and Drijfhout et al., 2004; van Sebille et al., 2009], whereas the exchange of waters from Agulhas rings to the northward flowing Benguela Current is dependent on their decay rate, mixing in the Cape Basin and pathway [de Steur et al., $2005]$.

As the individual features of the Agulhas region are obscured by high spatial and temporal variability, such processes make it difficult to realistically resolve and simulate the AL in numerical models, as well as plan an effective observation method. Numerical models do not necessarily realistically simulate the Agulhas system. Due to the highly nonlinear nature of the variability (rings, filaments, jets), outputs are highly reliant on model specificities and horizontal resolution [Barnier et al., 2006]. Durgadoo et al. [2013] suggest that when the resolution is increased, the amount of leakage decreases. 
However the dynamics are far from regular due to the complexity of the region and the set up of different models may affect the transport values resulting in varying estimates, as with increasing horizontal resolution the sensitivity of the AL to the Agulhas Current transport is found to decrease [Loveday et al., 2014]. Equally the leakage in coarse resolution, non-eddying models, allows a higher fraction of Agulhas waters into the Atlantic [Dykstra and de Ruijter, 2001] than in eddy resolving models, hence the role of Agulhas rings also needs to be quantified. To be able to compare models output using one robust method is currently a major gap in the research, which we attempt to bridge.

The outputs of high resolution regional hindcasts of the Agulhas region can be utilised to identify a method to measure volume, heat and freshwater transports of the AL across a fixed boundary such as the GH line. Statistical methods can then be used to determine the drivers of variability in the AL. Once these are identified they can be compared to those produced by lower resolution climate models. A better understanding of the processes influencing the AL may increase the understanding of the Agulhas system role in global climate and circulation. Beal et al. [2011] identified evidence that the AL is increasing with climate change, linked to a warming trend in the Agulhas system since the 1960s and southward shift of the Subtropical front. Over 2-4 decades the warm salty water that enters the South Atlantic is advected northwards (Ruhs et al., 2013; Weijer et al., 2002), its influence on the buoyancy balance affects deep water formation, the AMOC and thus global climate. An increase in leakage has the ability to increase the salinity of the South Atlantic, enhancing the meridional pressure gradient and influencing deep water formation (Weijer et al., 2002). Paleoceanographic studies and foram assemblages indicate that fluctuation in the strength of the AL are linked to the glacial/interglacial cycles and periods of reduced AMOC [Peeters et al., 2004; Caley et al., 2014]. The increase in $\mathrm{AL}$ towards the end of glacial periods, suggest that the AL may play a restorating role in the interglacial global climate as well as ocean overturning [Beal et al., 2011]. The water masses carried by Agulhas rings can become entrained in the South Atlantic branch of the AMOC, transporting temperature and salinity anomalies into the North Atlantic [Biastoch et al., 2008]. With the predicted increase in AL, if the 
AL has the potential to affect climate it is important for climate models to reproduce the correct processes of variability of the AL. Currently, climate models are of coarse resolution and unable to accurately simulate mesoscale processes and thus reproduce the AL incorrectly, so what are the consequences for the AL mechanisms of variability? By understanding the sensitivity of the processes of variability of the AL to model resolution, climate model simulations could be used to identify what may happen in the future and over longer time periods (decadal and multidecadal variability) than is possible in high resolution regional hindcasts.

\subsection{Quantification of the AL}

The extreme complexity of the Agulhas region as a whole and that of the AL has led to no consensus on a mean state value of the AL [Table 2.1]. Estimates depend highly on the model (resolution, vertical levels), the method used, as well as the time and location where the AL is assessed. Many methods have been explored in existing literature, however it is difficult to compare estimates as not one robust method has been established which can be used for inter-comparison of AL estimates between different models. In order to create such a method, a thorough review of existing methods is needed, highlighting the strengths and weaknesses of each. The following review acts to present the literature by splitting it into the two main method types: Eulerian and Lagrangian. A critical assessment of the current methods will provide insight into which are the most effective and repeatable.

\subsubsection{Eulerian}

The original [Dijkstra and De Ruijter,2001; Matano and Beier, 2003; Treguier et al., 2003; Reason et al., 2003; Hermes et al., 2007] and most direct method is to integrate velocity across a particular section as a function of depth and distance from the African coast. The GH line is preferred for such a method, however not all the transport across the GH line is expected to be due to AL. The complexity forms as such a method needs 
to try and distinguish only the waters of Indian Ocean origin. One possibility is to isolate only waters that exist above certain thresholds of temperature and salinity [Van Sebille et al., 2010] as the AL waters are expected to be warmer and more saline due to their Indian Ocean origin than those of the South Atlantic. This is complicated by the vigorous mixing that occurs in the Cape Basin. Hence, Van Sebille et al. [2010] found that only half the leakage can be directly measured in this way. An alternative is to isolate only subsections of a particular section and integrate all transports within this region. When choosing a subregion, the offshore distance can be identified as the point beyond the eddy corridor (maximum float crossing location at $\approx 900 \mathrm{~km}$ offshore) and the GH jet ( $\approx 200 \mathrm{~km}$ offshore). The difficulty comes when identifying the depth of the subregion as Agulhas rings can extend to the ocean floor, however they are not continuously present and integration over the full depth can lead to spurious estimates of the leakage [Doglioli et al., 2006]. Van Sebille et al. [2009] suggest that no leakage occurs below $2000 \mathrm{~m}$ which agrees with ideas that there is a potential shallowness of the AL (restricted to the upper $1500 \mathrm{~m}$ ) as relative vorticity is low below $1200 \mathrm{~m}$ with limited mass carried by rings below this depth [de Ruijter, 2006]. Such Eulerian methods estimate fluxes by imposing water mass criteria [Loveday et al., 2014]. This can be a limitation of such methods in regions with high eddy activity, as the leakage is underestimated [Swart et al., 2008].

If the AC is assumed to have a regular flow, then a simple index (similar to that used in the North Atlantic in the RAPID-MOCHA programme) from the conservation of mass may be found through the first order equation of Van Sebille et al. [2009]:

$$
T_{A C}=T_{A L}+T_{A R C}+T_{R}
$$

where $\mathrm{T}$ stands from transport, $\mathrm{T}_{A L}$ is measured far from the retroflection area (across the GH line), $\mathrm{T}_{A R C}$ is measured far from the Cape Basin, and $\mathrm{T}_{R}$ is the residual water masses that have not left the domain through one of these sections after a relatively long integration (5 years in van Sebille et al., 2009). Such an equation allows for the magnitude of $\mathrm{AL}$ to be found as a function of the $\mathrm{T}_{A C}-\mathrm{T}_{A R C}-\mathrm{T}_{R}$. Difficulties 
arise when trying to separate $\mathrm{T}_{A R C}$ from other westward flowing water masses and jets confined mainly within the Antarctic Circumpolar Current. Thus, such an index is sensitive to latitudinal shift in the Southern Ocean frontal systems [van Sebille et al., 2009b]. Equally the ratio between the $\mathrm{T}_{A C}$ and $\mathrm{T}_{A R C}$ can be used to estimate the $\mathrm{T}_{A L}$ through volumetric fluxes of the three-dimensional velocity field in a numerical model, however this encounters similar problems and can not be compared to observations as such data is not available [Dijkstra and de Ruijter, 2001; Hermes et al., 2007].

The method by Souza et al. [2011] combines altimetry with ARGO floats to determine the vertical structure of Agulhas rings. Although the rings (anticyclonic in nature) can be tracked effectively by their elevated SSH signature, they are difficult to quantify and fix a per ring volume transport to, due to the variability in diameter and dissipation as they drift into the Atlantic [Dencausse et al., 2010]. Similar to the use of SSH to track Agulhas rings, through manipulation of the thermal wind equation and the changes in sea surface elevation $(\eta)$, geostrophic velocities $\left(\mathrm{cm} / \mathrm{s}^{-1}\right)$ can be calculated [Le Bars, 2013]. When these values are integrated along a section to a predetermined depth it can also provide an estimate of AL. Both rings and filaments can be tracked via thermal infrared satellite imagery [Lutjeharms 1996], the contribution of these to the AL is estimated by the rate at which filaments and rings are advected across a section into the South Atlantic.

\subsubsection{Lagrangian}

The majority of recent model studies have preferred the use of Lagrangian methods to measure AL. Numerical model simulation use the transport of advected artificial water parcels, released from a certain location $\left(32^{\circ} \mathrm{S}\right)$ and tracked for a defined time period (5 years) [Speich et al., 2001; Biastoch et al., 2008, 2009; Ruhs et al., 2013]. The AL is then defined by the portion of parcels exiting the AC through the $\mathrm{GH}$ line, or west of the retroflection towards the South Atlantic. When compared to the estimated leakage from real ocean drifters and floats the results agree with recent high resolution models [Diglioli et al., 2006; Richardson et al., 2007]. Floats in the real ocean are however 
limited in number which restricts the statistical analysis carried out and estimates are not directly comparable. The use of numerical floats to estimate AL has been favourable to Eulerian methods as one method can be applied to different models allowing direct comparison of estimates [Durgadoo et al., 2013]. However, the use of numerical floats does not provide a complete AL estimate. Numerical floats or particles are fixed to grid points and dependent on the grid size, they provide no information within each grid cell which prevents any contribution from the unresolved submesoscale processes (filaments and jets) which are known to contribute to the AL [Lutjeharms and Cooper, 1996]. The main problem with Lagrangian estimates from numerical models is that the method is often misunderstood or incorrectly used. Differences in the method set up as well as how and where the float trajectories are integrated (final or initial) prevents direct comparison of transport estimates. Equally, the time period used and the use of repeated time periods can effect the estimate of AL as assumption of repeatability may bias the true variability of the system. Finally Lagrangian methods are computationally expensive.

\subsection{Conclusion}

The majority of studies of the AL rely heavily on numerical ocean models, as there is presently no in-situ observing system. These models do not necessarily realistically simulate the Agulhas system. Different models have contradicting arguments for the magnitude and variability of the $\mathrm{AL}$, leakage estimates range from 5-15 Sv with fairly large uncertainty. Moreover many different methods are used to estimate the leakage which leads to independent, incomparable values. Although Lagrangian methods have been the preferable choice, an Eulerian approach is needed to be easily applied to a large amount of model output. In order to estimate the AL in a way that is comparable across many models configurations, the GH line provides a boundary between the Atlantic and Indian ocean, across which fluxes can be computed. Unlike with the Lagrangian approach, Eulerian methods calculate transports through this boundary allowing both 
advective and diffusive components to contribute, as well as heat and freshwater fluxes to be quantified. Variability should also encompass the large scale, mesoscale and submesoscale processes. Using such a defined boundary can be replicated across all models, even with varying resolutions to establish a comparable method. Due to the turbulent nature of the Cape Basin, identifying separate water masses is complicated and is the main drawback of such Eulerian velocity-based transport estimates. Here it is seen that direct quantification of Agulhas rings underestimates the leakage magnitude, whilst full depth Eulerian measurements over estimate the transport. With the potential of increasing leakage to warm the climate, the importance of the Agulhas system and its role in the global climate and circulation makes understanding the drivers of variability in the past and for the future very important. 


\section{Chapter 3}

\section{Methods}

A robust Eulerian method is needed to directly compare many numerical models. This method needs to be designed to systematically investigate the drivers of variability rather than to compare the mean AL, as this is likely sensitive to the model design. Here using six ocean simulations of varying horizontal resolution (summarised in Table 3.1), we compare the ability to represent the structure along the GH Line and investigate the effect of resolution on the dominant drivers of AL variability.

\subsection{Model Outputs}

The hydrodynamic simulations utilised in this study are ORCA12, ORCA025 and IPSLCM5 [Deshayes et al. 2013; Dufresne et al 2011] based on the Nucleus for European Modelling of the Ocean (NEMO) code, AGUa0.10 [Backeberg et al., 2009; 2014] and INDa0.12 [George et al., 2010] constructed from the Hybrid Coordinate Ocean Model (HYCOM) and the Loveday et al. [2014] ARC112i configuration from the Regional Oceanic Modelling System (ROMS). Although each of the simulations differ in their configuration they have comparable resolution and time periods to allow for intercomparison. 


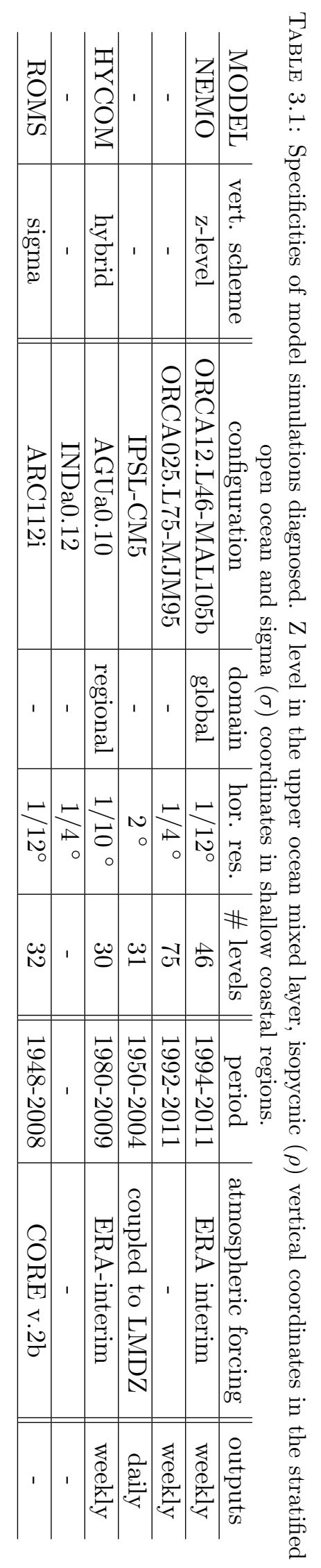




\subsubsection{NEMO}

ORCA12 and ORCA025 use NEMO code that operates on a global tripolar quasiisotropic grid incorporating the z-level Ocean Parallelise (OPA) ocean model with the Louvain-la-Neuve (LIM) sea ice model [Madec, 2008; Fichefet and Morales Maqueda, 1997]. The horizontal resolution of ORCA12 is $1 / 12^{\circ}$. It has 46 vertical z-levels with a partial slip lateral boundary and linearly filtered free surface. Bathymetry is a combination of Etopo1 of the National Geophysical data Center and GEBCO08. A momentum advection scheme is used to conserve energy and enstrophy [Le Sommer et al., 2009]. Vertical mixing uses a turbulent closure model (TKE, Blanke and Delecluse, 1993]. ORCA12 outputs are available from 1994-2012 as a 5 day averages. For comparison, the $1 / 4^{\circ}$ resolution ORCA025 configuration is used. The bathymetry is derived from the Etopo2 saltellite-based bathymetry file [Smith and Sandwell, (1997)]. Both configurations are produced by the DRAKKAR group and utilise the same restoring factors and atmospheric forcings. Surface heat fluxes are calculated from atmospheric conditions and upper ocean characteristics using bulk formulae. Sea surface salinity is restored to climatology with the time scale of the simulation.

As an example of a coarse resolution climate model, the $2^{\circ}$ IPSL-CM5 model is used. Developed by the Institut Pierre Simon Laplace (IPSL), the IPSL-CM5 is an Earth System Model (ESM) that incorporates a consistent suite of models with various degrees of complexity and resolution [Dufresne et al., 2013]. The ocean component is based on NEMOv3.2 with ORCA2 configuration on a isotropic Mercator gird with 31 vertical depth levels. Here daily outputs for the period 1980-2004 of a historical simulation are analysed.

\subsubsection{HYCOM}

A regional version of the HYCOM model is used, which has been previously shown to represent the Agulhas system well [Backeberg et al., 2014]. HYCOM combines isopycniccoordinate and fixed grid ocean circulation within its primitive equation framework 
[Bleck 2002]. The AGUa0.10 configuration has a spatial resolution of $1 / 10^{\circ}$ with 32 vertical layers. Vertical resolution is determined each time-step by an interchanging hybrid distribution. With each vertical interchange, $\mathrm{Z}$ levels are used where representing the upper ocean mixed layer, isopycnic $(\rho)$ layers in the stratified open ocean and $\sigma$ coordinates in the shallow coastal regions and the bottom layers with emphasis always placed on restoring the grid to isopycnic coordinates [Backeberg et al., 2014]. This grid realistically resolves vertical density gradients thus can effectively simulate fronts and the thermocline. AGUa0.10 outputs weekly average values for 1980-2010. Within this study it was found that the AGUa0.10 simulation has a salinity bias which is further discussed later. For comparison, the coarse resolution HYCOM configuration named INDa0.12 is used. INDa0.12 has a spatial resolution of $1 / 4^{\circ}$ and is provided as weekly average values for 1980-2012.

\subsubsection{ROMS}

The final simulation ARC112i, uses ROMS that has high-order numerical schemes to solve the incompressible hydrostatic primitive equations of fluid dynamics, discretized in the stretch terrain following vertical co-ordinates and horizontal curvilinear co-ordinates [Penven et al., 2001; Marchesiello et al., 2003; Penven et al., 2006]. ROMS is a splitexplicit, free surface model which utilises a terrain following vertical coordinate system $(\sigma)$. In ARC112i, the horizontal resolution is $1 / 12^{\circ}$ and there are $32 \sigma$ levels which follow the bathymetry and are stretched towards the surface to establish the vertical resolution [Loveday et al., 2014]. The outputs are available weekly for 1948-2008, this is the longest configuration analysed in this study.

\subsubsection{PAGO Extraction}

A major challenge when intercomparing models is the difference in the type of horizontal and vertical grid used. In this study, the Physical Analysis of a Gridded Ocean (PAGO) tool was used [Deshayes et al., 2014]. PAGO takes the two coordinate end points of 
the GH line and connects the nearest model grid points in a stepwise sequence of faces. The size of the staircase depends on the model resolution [Figure 3.1]. This type of extraction removes the possible interpolation errors when using different grids [Barrier et al., 2014]. PAGO allows the same line to be extracted and compared from different grid configurations. The challenge of using PAGO extractions in this study falls when analysing the velocity sections. The velocity are given through two faces representing the $\mathrm{U}$ and $\mathrm{V}$ directions. Depending on the orientation of the flow field the velocity is either positive or negative. If the flow is orientated so that the $\mathrm{u}$ component $\geq 0$ and $\mathrm{v}$ $\leq 0$, velocities switch between positive and negative values giving a striped effect across vertical sections. When performing spatial spectra the stepwise extraction produces peaks at high frequencies which overlay and prevent the analysis of variability at spatial scales smaller than $50-100 \mathrm{~km}$ as discussed later.
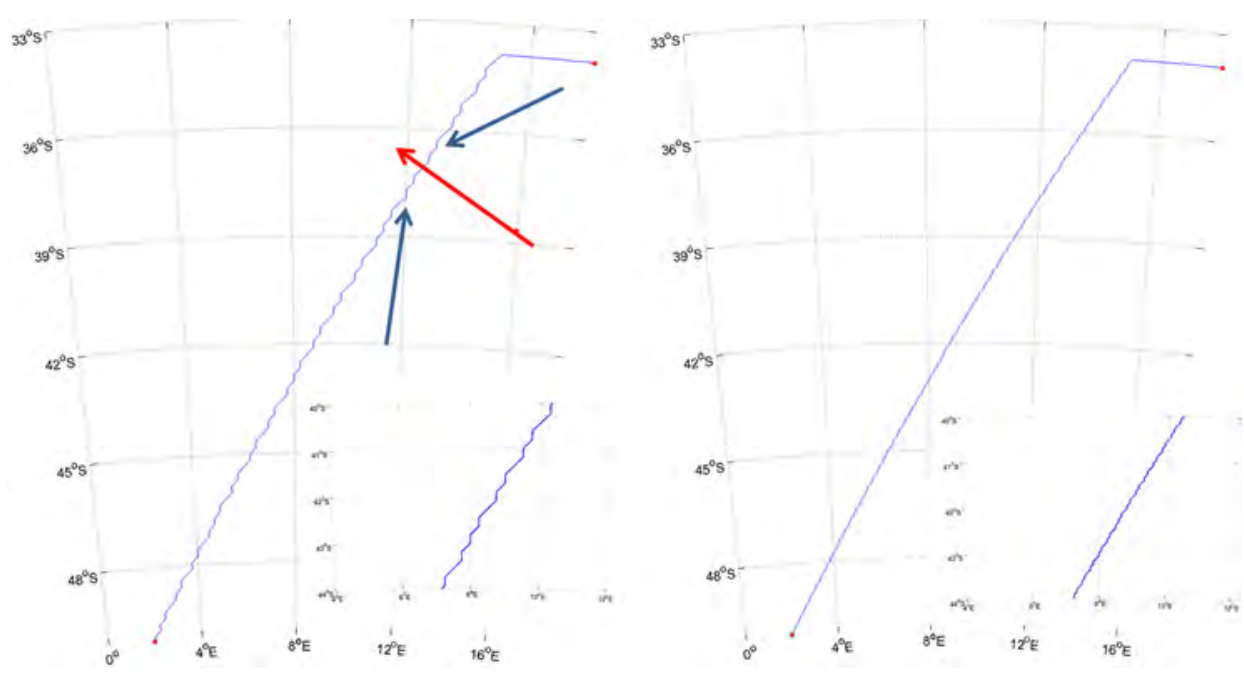

Figure 3.1: The full GH line and zoom of the stepwise PAGO stair-case extraction steps for ORCA025 (left) and ORCA12 (right). The size of the staircase depends on the grid resolution, with sections following the shortest great circle between end points. The resulting section velocities depend on the orientation of the current to the $\mathrm{u}, \mathrm{v}$ faces. A current orientated in the direction of the blue arrow will display both negative and positive values resulting in velocity stripes, but only positive values if orientated in the direction of the red arrow.

\subsection{Quantifying the Agulhas Leakage}

If the GH line structure is represented well, then the GH line acts as a boundary between the Atlantic and Indian Oceans and thus Indian Ocean water masses passing by can be 
identified and measured as AL. If the water masses located in observations are well defined in the models and remain present even when there are/are no rings present and flow is high/low, it is possible to use the water masses and stratification to define and quantify the AL. Finding a robust method for this that works across all models is a challenge. Firstly, the thresholds need to be established in order to define an area of the section composing the leakage. Transport is then the integration of the velocities held within this area (limited in depth and offshore extent). There are two possible forms of calculated transport: NET transport is the complete integration of the area captured within the threshold layers and TOTAL transport which integrates only the positive velocities within this area. In the NET transport anticyclonic velocities related to rings will mostly cancel out, reducing the overall AL transport. On the other hand the TOTAL transport will only capture the north-westward velocities of rings with no compensating return flow, which will overestimate the leakage.

\subsubsection{Van Sebille Thresholds}

The Eulerian method of van Sebille et al. [2009b] takes the general assumption that at the GH line the Agulhas leakage is represented by the warmest and most saline water masses. Using the thermohaline properties of the flux at the GH line in the $1 / 10^{\circ}$ AGO1 numerical model (based on NEMO code), the optimum thresholds are $14.6{ }^{\circ} \mathrm{C}$ and 35.3 PSU [van Sebille et al., 2009b). The integration domain is controlled by the isohalines rather than the isotherms, as expected. As the waters move through the Cape Basin, they experience cooling, leaving salinity as the dominant signal. Agulhas leakage is thus better defined by its salinity signature than by temperature [van Sebille et al., 2010a; Biastoch et al., 2008]. In this study, these thresholds were initially used to estimate the AL in the three models and to evaluate how well the thresholds hold. Van Sebille et al. [2009b] found that their thresholds produced a measure of AL transport that was a factor of two lower than the magnitude of the AL from Lagrangian floats within the same method. This highlights an underestimate of the mean state when using such a threshold method. However variability is represented well. 


\subsubsection{Validation of Threshold Methods}

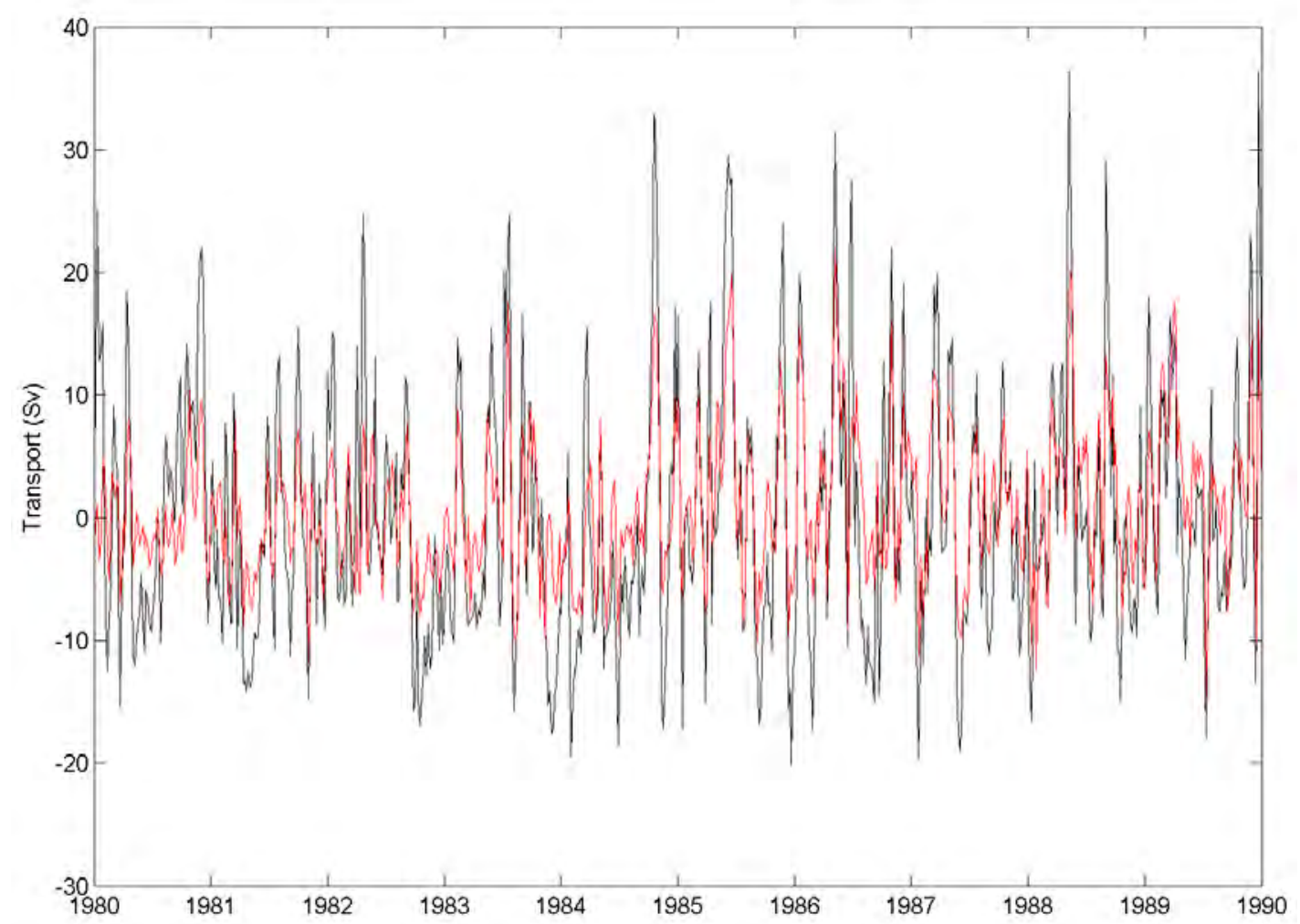

Figure 3.2: Time series comparison between the Agulhas leakage transport estimated using the Eulerian integration method proposed in this study for the ARC112i output (red line) and the transport from an Eulerian passive tracer method for ARC112i (black line) calculated by Loveday et al. [2014] for 1970-1990.

Applying the van Sebille thresholds to the GH section from the ARC112i simulation produces the time series shown in Figure 3.2 (red line). The second AL transport estimates are provided by a Eulerian passive tracer computed by Loveday et al. [2014]. Tracers are added to the model with values of 1 in the Indian Ocean east of $70^{\circ} \mathrm{E}$ and 0 in the Atlantic waters west of $20^{\circ} \mathrm{W}$. The tracer is free to diffuse and advect with the flow fields and follows the Indian Ocean waters to the south and west of the African continent [Le Bars et al., 2014]. The computed flux of tracers that pass into the Atlantic across the GH line is then defined as the leakage. When compared to such a passive tracer method within ARC112i, the threshold time series utilised in this study captures the AL variability well: it captures $60 \%$ of the 'true' leakage (passive mean $=18.7 \mathrm{~Sv}$, threshold mean $=11.24 \mathrm{~Sv})$ yet nearly all $($ correlation $=0.9)$ of the variability. The two time series of AL estimates are shown in Figure 3.2. In this study we are solely interested 
in capturing the correct variability of the Agulhas leakage in an Eulerian estimate. This result thus validates that a threshold approach is appropriate. However, the threshold values used need to be evaluated as the van Sebille thresholds are model specific and may not correctly estimate the AL in other models. Several other approaches are assessed.

\subsubsection{AC1 Line}

We tested a second method which set out to identify model specific values by taking temperature and salinity thresholds from the core of the $\mathrm{AC}$ using the $\mathrm{AC} 1$ line in each model. The AC1 line is located between $30.8^{\circ} \mathrm{S}, 30.2^{\circ} \mathrm{E}$ and $37.8^{\circ} \mathrm{S}, 38.8^{\circ} \mathrm{E}$ [Figure 2.1]. When computed using this method, the AL transports for each model were very low (ranging between 4-10 Sv) and the variability was less well represented than with the van Sebille thresholds (when comparing with the passive tracer method for ARC112i). Transport values would frequently drop to zero, when thresholds were greater than the temperature and salinity values present across the whole section. This is probably due to the fact that the temperature and salinity threshold values are taken from the major core of the $\mathrm{AC}$ and have not been adjusted for the loss of heat by air-sea interactions and mixing in the Cape Basin. The resulting thresholds are therefore all higher than those of van Sebille et al. [2009a], thus the integration domain is reduced, decreasing the leakage volume transport. The method thus needs to take into account the loss of heat through air-sea interactions and mixing that occurs between the AC1 and GH line.

\subsubsection{Potential Vorticity}

Potential vorticity (PV) identifies stratification in the ocean. The stratification produced by the transition from warm, saline Indian Ocean water to the cool, fresher Antarctic Intermediate Water below is expected to be represented by a maximum in PV. PV is estimated by first calculating the squared Brunt-Vaisala frequency $\left[N^{2}\right]$ from the equation 


$$
N^{2}=\frac{-g}{\rho} \times \frac{\partial \rho}{d z}
$$

where $\mathrm{g}$ is $9.81 \mathrm{~ms}^{-2}, \rho$ is potential density given by $\rho=\rho(T, S, p)$ and $\frac{\partial \rho}{\partial z}$ is the change in density with depth. From the Brunt-Vaisala frequency, the potential vorticity can be calculated as

$$
P V=f \times N^{2} / g
$$

where $\mathrm{f}$ is the Coriolis parameter and $\mathrm{PV}$ has units of $\mathrm{ms}^{-1}$. By isolating the Indian Ocean water masses as those above the maximum of PV, a PV threshold may be used as a another method to define the AL integration area. We noted that using this method based on PV is able to pick up the passing of Agulhas rings accurately. However, similar to the AC1 line method, the magnitude and variability of the AL are lower than those obtained with the van Sebille thresholds. Therefore this method was not used in the final analysis.

\subsubsection{Including Bias}

AGUa0.10 has a salinity bias, on average 0.2 lower than observed values. By implementing the van Sebille thresholds, with salinity as the dominant determinant of the leakage domain, AGUa0.10 would have zero transport in the mean (salinity values across the section never reach 35.3). This illustrates that different model configurations are likely to have differing temperature and salinity bias as the values depend on the atmospheric forcing, bulk formula and restoring quantities used. In order to provide a robust method which is able to be replicated independent of the model setup, the temperature and salinity thresholds need to be adapted to any temperature and salinity bias.

As seen when van Sebille thresholds are used, ARC112i responds well with the variability of the AL captured fully, relative to that estimated by a passive tracer method [Figure 


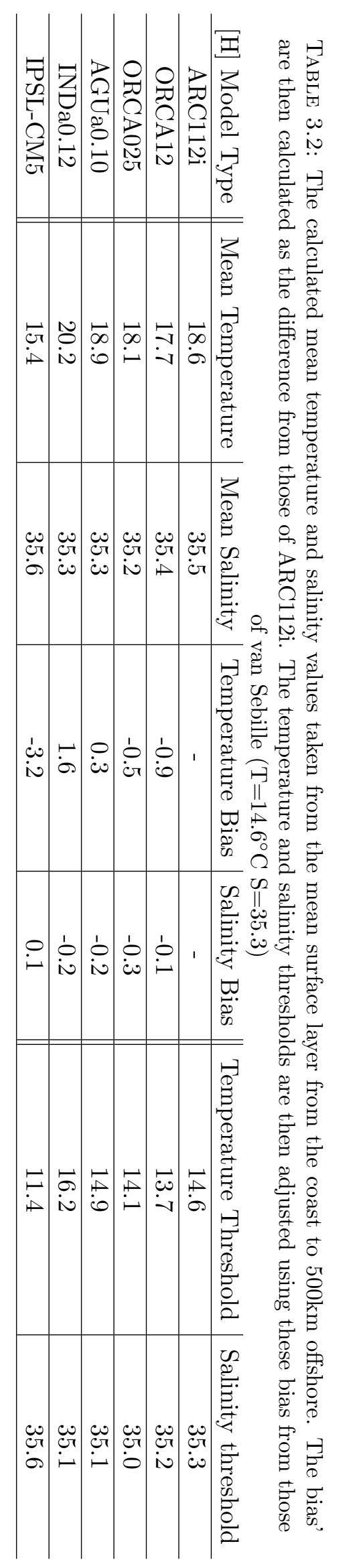


3.2]. It may then be assumed that the thresholds are adequate at capturing the variability of the AL in ARC112i. Using this assumption the temperature and salinity bias of the other models can be assessed. In ARC112i the mean temperature and salinity values for the surface layer from the coast to $500 \mathrm{~km}$ offshore on the GH line are calculated and shown in Table 3.2. This domain is chosen as it lies within the region of leakage in all the models. These values can then be estimated in the other models and compared to ARC112i. Differences are then considered as a bias and the integration thresholds are adjusted accordingly (Table 3.2 . .

\subsection{Barotropic Streamfunction}

To investigate the horizontal structure of the mean circulation through the GH line, the barotropic streamfunction was calculated for the mean velocities of ORCA12 from 19942012. The barotropic streamfunction begins with the divergence equation integrated over depth, neglecting fluctuations of the sea surface height:

$$
\frac{\partial U}{\partial x}+\frac{\partial V}{\partial y}=0
$$

where: $U=\int_{-H}^{0} u d z$ and $V=\int_{-H}^{0} v d z$ are the barotropic velocities. The solution to equation 3.3 is the barotropic streamfunction $(\psi)$ defined as

$$
\frac{\partial \psi}{\partial y}=-U \quad \text { and } \quad \frac{\partial \psi}{\partial x}=V
$$

By convention, we set the value of $\psi$ to 0 over land. Positive values $\psi$ represent cyclonic (clockwise) flow and negative values anticyclonic (anticlockwise) flow (in the southern hemisphere). 


\subsection{Spectral Analysis}

Power spectral analysis is used to assess the time scales and spatial scales of AL variability in each model. When used in the time domain, a power spectrum transforms the time series into the frequency domain and quantifies the contribution of each frequency to the total variance. A multitaper approach was used to estimate both time and space spectra. Using this approach, the estimation bias is reduced by obtaining multiple independent estimates from the same sample. Each data taper is multiplied element-wise by the signal and each taper is pairwise orthogonal to all other tapers. The final spectrum is then obtained by averaging over all the tapered spectra. The calculated spectra then may show peaks (larger than the error bar) at dominant frequencies. Signals that fall within the error bar express no periodicity whether it be in time or space and can be assessed as a random process. Most ocean processes follow a red spectrum with the variance predominately decreasing from low to high frequencies. Any change of slope representing a transition from a flat spectrum to a red spectrum represents a damping timescale interpreted as the predominant frequency of variability. While the time spectra were calculated for the AL time series, the spatial spectras (wavenumber spectra) were performed for the surface layer velocities across the GH line in order to identify the spatial characteristics of current anomalies through the line.

\subsection{Final Method}

The final method utilised to compute the AL volume transport in the following analysis, follows the algorithm outlined below: 


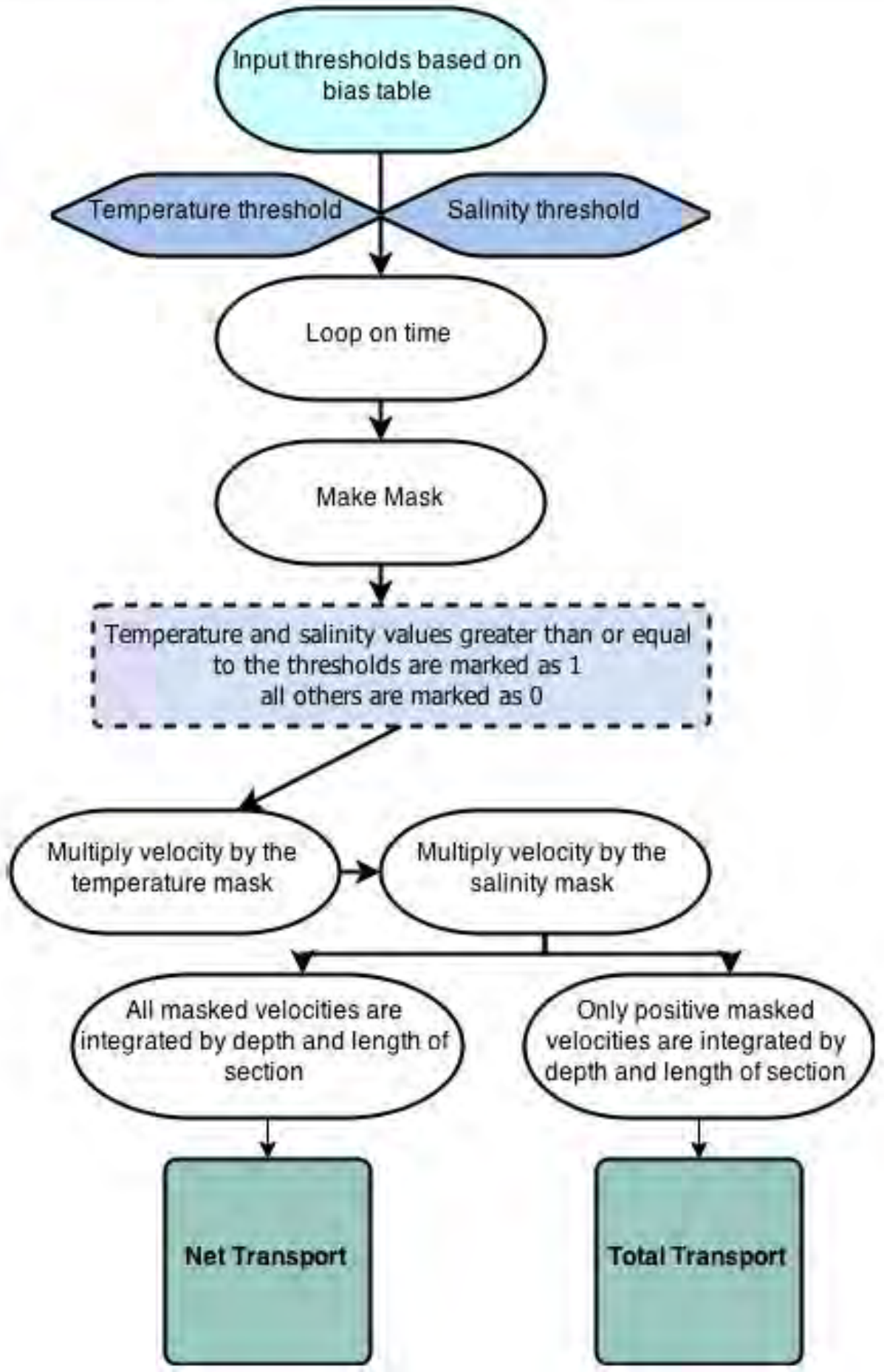





\section{Chapter 4}

\section{Results}

\subsection{Validation of High Resolution Hindcasts}

We will first focus on the series of three hindcast simulations of the Agulhas region at high resolution to diagnose the mechanisms of variability of the $\mathrm{AL}$, as these are expected to be the most realistic. In section 4.4, we then compare these results with companion lower resolution $1 / 4^{\circ}$ simulations to determine whether the mechanisms of spatio-temporal variability of the AL are affected by resolution.

\subsubsection{Thermohaline Structure Along the GH Line}

Since 2004, the GH line has measured a full depth section of the Agulhas and Southern Ocean regions. Due to the extreme conditions of the Southern Ocean and great cost of ship based observations, the monitoring line is restricted to measurements in the middle of the austral summer (December-January). The observations can therefore only provide a temporal snapshot of the section. They do however represent the only observations of the thermohaline structures at depth along the section. By identifying the major water masses, especially those at depth which are not expected to be dependent on seasonality nor air-sea interactions, these observation provide a valuable base on which to evaluate whether regional hindcasts are representing the thermohaline structure realistically. Also 
as measurements are only taken within a time frame of 1-3 weeks the observations frequently cross through an Agulhas ring. This provides evidence on how such eddies affect the water column structure and can be used to compare with the effect of eddies in the simulations.

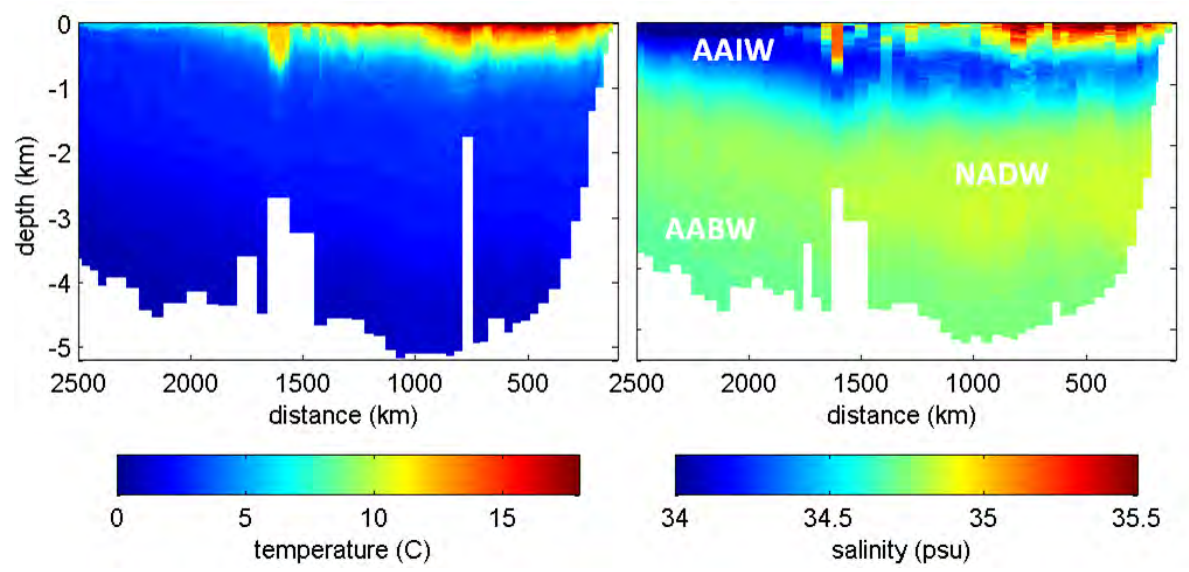

FiguRE 4.1: Observed temperature $\left({ }^{\circ} \mathrm{C}\right.$ ) and salinity (PSU) profiles from the 2008 BONUS-GOODHOPE cruise. The section is only a snapshot in time so cannot be used to identify temporal variability, however it is representative of how the water masses are positioned in the offshore direction and with depth. The major water masses are labelled in the salinity section: Antarctic Intermediate Water (AAIW), North Atlantic Deep Water (NADW) and Antarctic Bottom Water (AABW).

Water masses are large bodies of water with nearly homogeneous properties which are established during their formation. As a first step of validation of model output we only use temperature and salinity to identify the different water masses. In Figure 4.1 the surface waters from the coast to $1500 \mathrm{~km}$ offshore are occupied by the warmest and most saline waters. These can be associated with the exchange of water between the Indian Ocean and South Atlantic and thus constitute the AL. These waters are anomalously warm and saline because of the intense heating and evaporation that occurs in the Indian Ocean. The deepest waters of the GH line are made of Antarctic Bottom Water $(\mathrm{AABW}) . \mathrm{AABW}$ is amongst the densest water masses, formed by brine rejection and cooling by katabatic winds off the Antarctic peninsula which decrease the buoyancy (increase density) of surface waters. The density causes the water to sink to the bottom, with the cold temperature and intermediate salinity characteristics of the AABW. The most saline water at the GH line, which penetrates from the north between $\approx 2000$ 4000m deep, is North Atlantic Deep Water (NADW). NADW has high salinity due to 
the influence of the Mediterranean outflow on North Atlantic dense water formation. To the north of the maximum wind speeds $\left(\approx 48^{\circ} \mathrm{S}\right)$, here at $\approx 1500 \mathrm{~m}$ offshore, the waters converge resulting in downwelling (thermocline is deeper) and the formation of AAIW. AAIW is fresher, due to the influx of freshwater from ice melt, than the AABW and therefore less dense. It lies above the NADW and can be seen as the region of low salinity water subducting from the surface and moving northwards at $\approx 800 \mathrm{~m}$. The GH transect crosses a region known for high eddy kinetic energy (Goni et al., 1997) which is supplied by anticyclonic Agulhas rings or from instabilities in the frontal jets which generate cyclones (Richardson et al., 2003). The eddy observed in 2008 at about $1500 \mathrm{~km}$ offshore is likely an Agulhas ring detached from the retroflection, composed of Indian Ocean Central Water following the southern route [Dencausse et al., 2010].
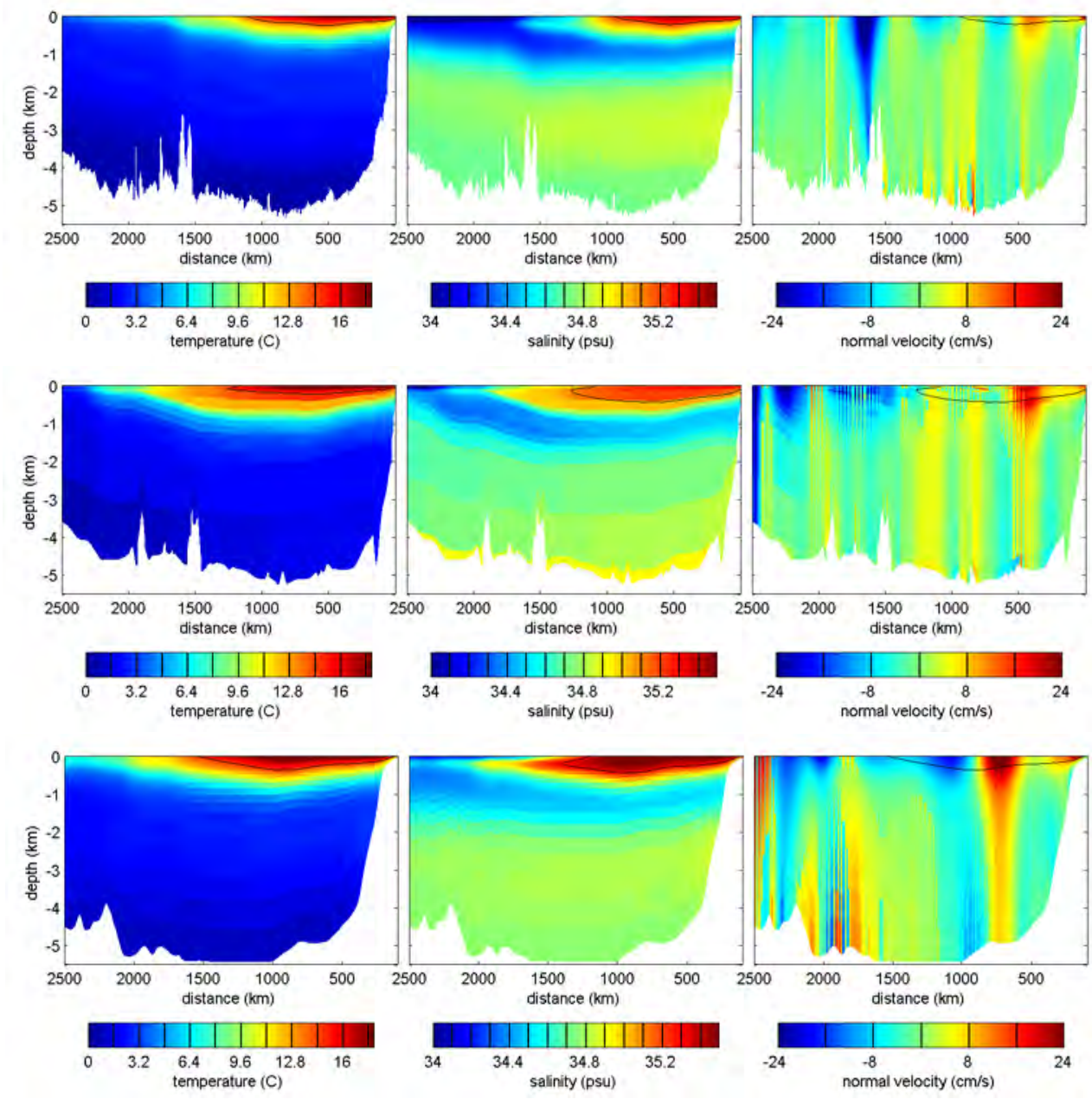

Figure 4.2: Temperature (left), salinity (middle) and normal velocity (right) in ORCA12 (top), AGUa0.10 (middle) and ARC112i (bottom). The overlaid black line represents the bias adjusted van Sebille thresholds for temperature and salinity and combined mask for velocity. 
ORCA12 is assumed to be the most realistic output due to the restorative forces applied. Indeed, across the GH line water masses are represented well [Figure 4.2 (top)]. In AGUa0.10 the average salinity is lower than those of ORCA12 and the observations, although temperature is represented well [Figure 4.2 (middle)]. This salinity bias is captured by the AL method and the integration threshold for salinity adjusted appropriately. Above $1500 \mathrm{~m}$, the water masses are in good agreement with the observations, with the Indian Ocean water lens and subduction of the fresher AAIW captured. Below $1500 \mathrm{~m}$ the highest salinity is seen at the seafloor. This is likely the contribution of the NADW, with the coldest waters of the AABW inflowing at depth from the south.

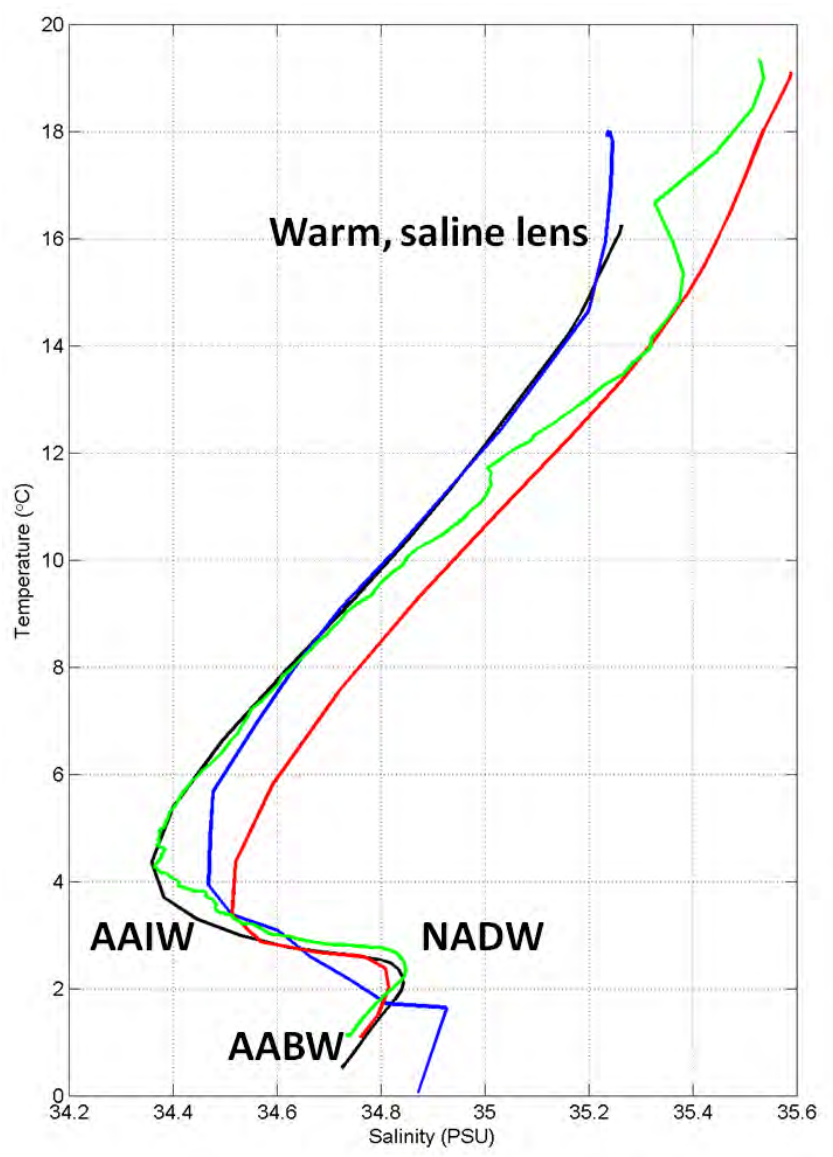

Figure 4.3: Temperature vs. salinity profiles for the Good Hope 2008 observations (green), ORCA12 (black), AGUa0.10 (blue) and ARC112i (red). Each temperature and salinity profile is taken at $500 \mathrm{~km}$ offshore.

Temperature/Salinity diagrams shown for each simulation at the time of the Good Hope 2008 observations [Figure 4.3] confirm that all three models reproduce realistically the different water masses expected at this location. Still, biases remain, at the surface 
and/or at depth for all models. Note that those biases are slightly different than detailed above [Figure 4.2], where the model's mean state was discussed. This study aims to identify the variability of the AL which is captured within the lens of warm, saline waters above $1000 \mathrm{~m}$. It is therefore not an issue that AGUa0.10 does not represent the lower water masses perfectly, but may be of importance for other studies which use the simulations, especially those related to deep circulation. The ARC112i output captures most of the water masses well [Figure 4.2 (bottom)]. However the salinity difference between the AAIW, NADW and AABW is less pronounced than that of the observations and can be seen by a shift to slightly increased salinities in Figure 4.3.

\subsubsection{Mean circulation through the GH line}

Velocity sections are a luxury of numerical models simulation, as such data is not readily available from observations. In the velocity profile of ORCA12 the main peak in positive velocity is located at $\approx 500 \mathrm{~km}$ offshore and extends to the sea floor. At $1600 \mathrm{~km}$ offshore there is an intense negative flow that is likely the position of the Subtropical Front, the northern most branch of the eastward flowing ACC. Similar to ORCA12, there is also a large peak in the positive velocity around $500 \mathrm{~km}$ offshore which extends to the seafloor in both AGUa0.10 and ARC112i. Both also have negative flows further offshore although the position of these is variable $(2400 \mathrm{~km}$ for AGUa0.10 and $2000 \mathrm{~km}$ for ARC112i). Apart from these features the mean velocity tends to zero for the majority of the profiles.

Mean velocities $500 \mathrm{~km}$ offshore which extend to the bottom in all three model simulations can be seen in the barotropic circulation [Figure 4.4]. The AC, the retroflection and the $\mathrm{ARC}$ are also clearly visible, with negative values indicating the anticyclonic direction of the subtropical gyre. A line of zero circulation separates the Agulhas region from the cyclonic flowing ACC. Across the GH line and within the AL domain, there are several recirculating streamlines. The most interesting is the stream function situated around $500 \mathrm{~km}$ offshore (black dot in Figure 4.4). This is the position of the peak in positive velocity in the ORCA12 sections, which sits at a location where the streamfunction lines have a north-westward direction. Although the line is ultimately connected to both the 
Agulhas Current System and the Atlantic subtropical gyre, it may not be interpreted as a direct mean route from the Indian Ocean to the South Atlantic Ocean. Instead, the multiple recirculations reveal the large influence of topography on the barotropic streamfunction. Hence, if the mean flow through GH line at $500 \mathrm{~km}$ offshore is related to a topographic feature, it would be expected to be present in all three models.

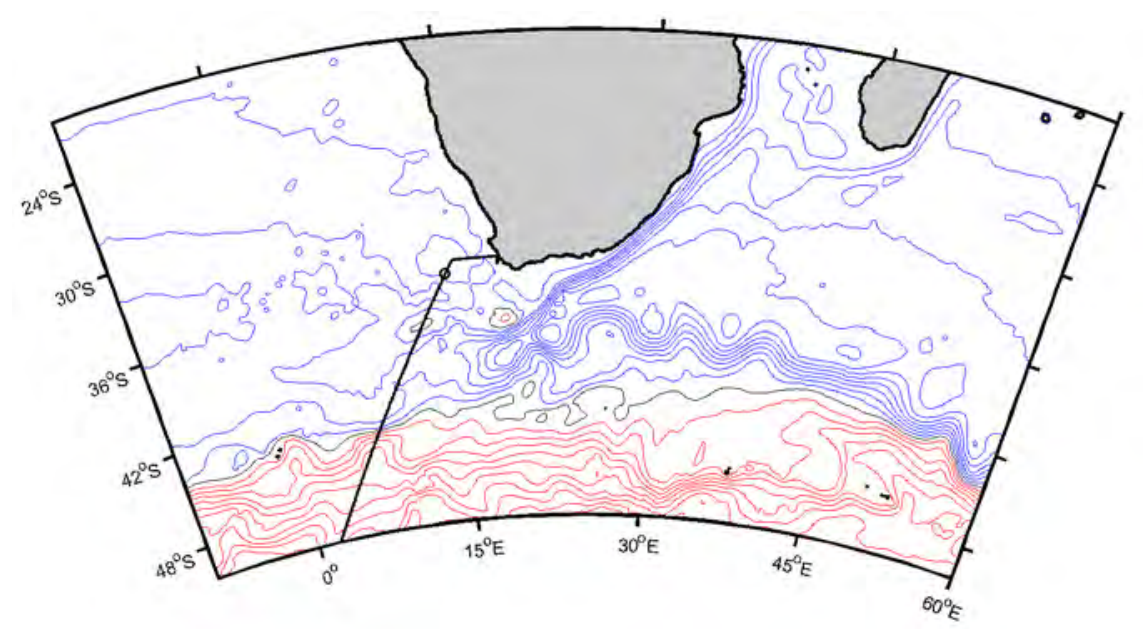

Figure 4.4: The barotropic stream function (equation 3.4 for ORCA12 (in Sv). Red lines indicate cyclonic circulation and blue lines anticyclonic circulation, the thin black line represents the zero contour. The GH line is overlaid in black. The location of a bathymetric feature $500 \mathrm{~km}$ offshore is circled.

\subsubsection{Anomalies in Thermohaline Structure Along the GH Line}

Agulhas rings are thought of as the predominant vehicle of exchange. The passing of a ring is likely to disrupt the thermohaline and circulation structure. The mean sections may therefore represent the average flow between times of no flow and times of elevated flow associated with the passing of rings. How does the structure change when rings pass through?

When isolating a single time step when velocity is anomalously high in ORCA12, two rings appear to be passing the GH line [Figure 4.5 (top)]. One at $\approx 400 \mathrm{~km}$ offshore and the other at $\approx 800 \mathrm{~km}$. Similar to the eddy observed in the 2008 Bonus-Goodhope line, the passing of the eddy depresses the isohalines and isotherms to a depth of $\approx 2000 \mathrm{~m}$. The rings enhance stratification and hold the warm, saline water masses within their structure. As a result, the influence of the eddies increase the area of leakage. The 
rotational velocities of the eddies are seen clearly in the velocity section with maximum velocities held above $1500 \mathrm{~m}$ but a remaining footprint extending to the sea floor.
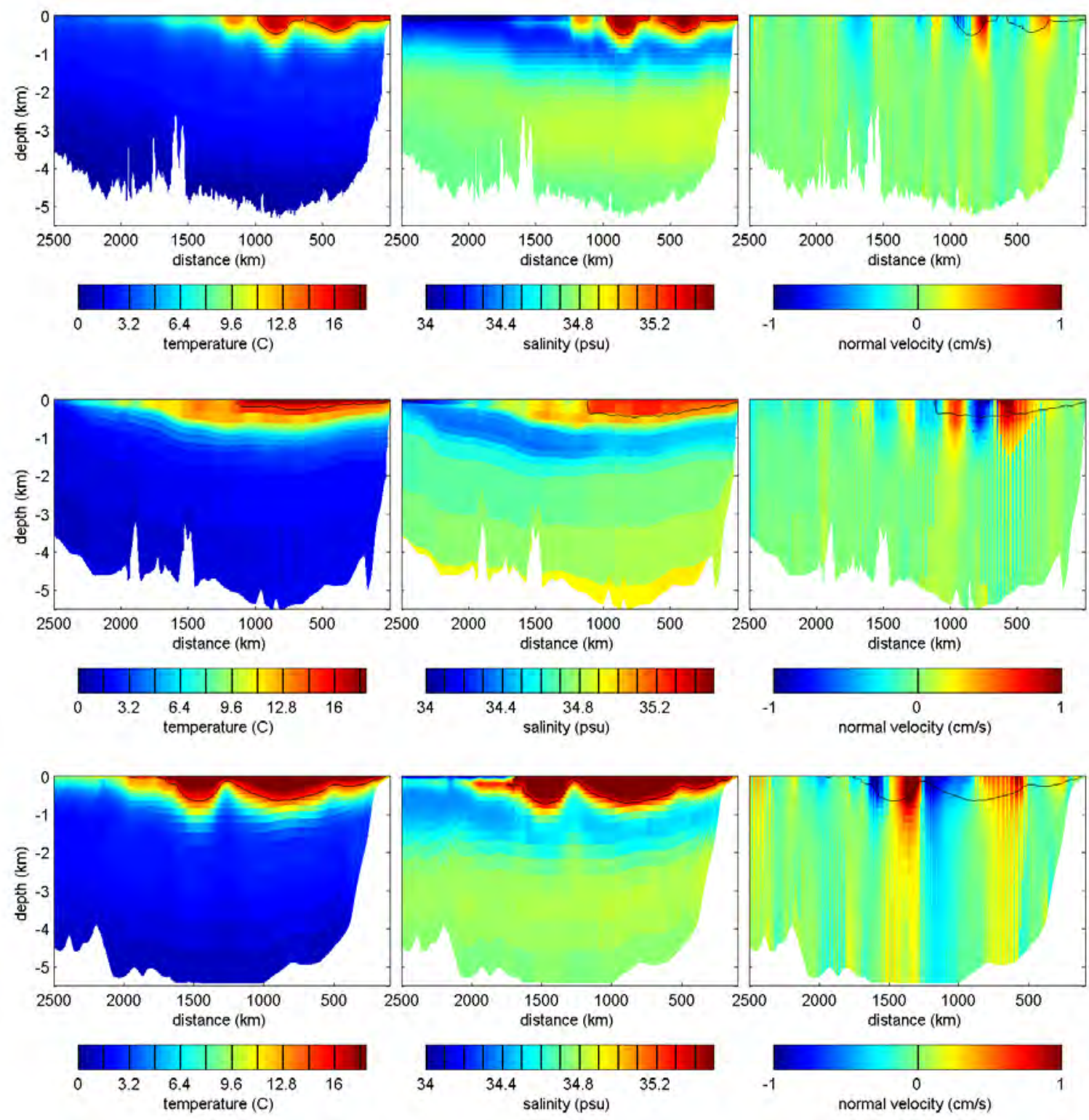

FIGURE 4.5: Snapshots of temperature salinity and normal velocity at time steps when the AL is maximum: in July 1996 for ORCA12 (top), in March 2004 for AGUa0.10 (middle) and in February 1962 for ARC112i (bottom). Black lines as in Figure 4.2 at the corresponding time steps.

At times of high flow in AGUa0.10 there are two strong velocity anomalies similar to those seen in ORCA12 [Figure 4.5 (middle)], which can also be seen as sea surface height anomalies in the surface snapshots for the same time period [Figure 4.6]. However what differs in the AGUa0.10 section is that there is no corresponding anomaly in temperature and salinity. The AL region is thus not increased by the passing of a ring as observed in 
ORCA12. In ARC112i two large intense eddy structures are seen which have very high temperature and salinity signature and depress the isotherms and isohaline to a depth of $2000 \mathrm{~m}$ deep [Figure 4.5 (bottom)]. The associated velocity is very intense. Although the eddies disrupt the AAIW tongue slightly, the water masses are still well defined.
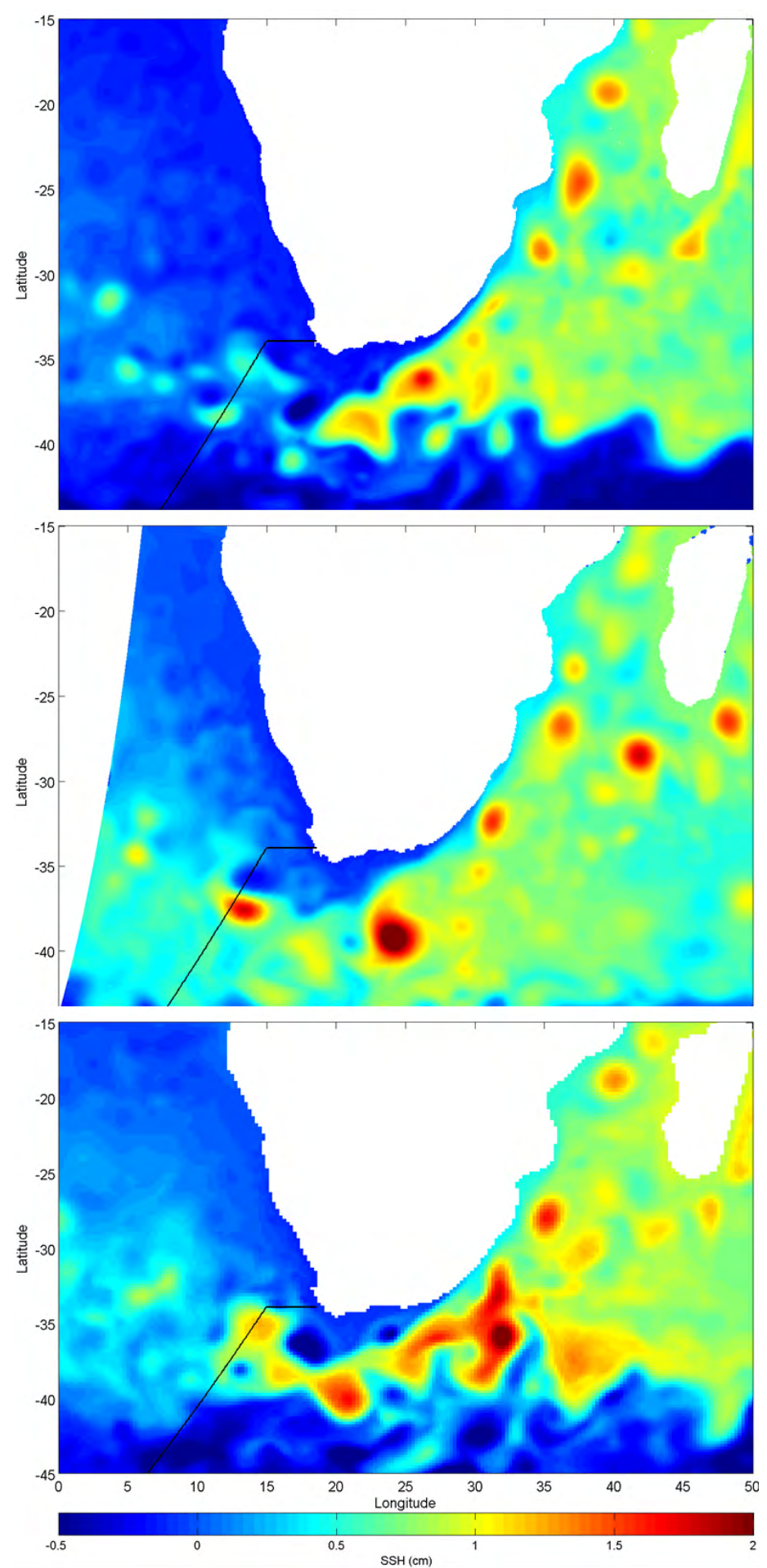

FiguRE 4.6: Snapshots of sea surface height (SSH) for the same time periods as Figure 4.5 for ORCA12 (top), AGUo0.10 (middle) and ARC112i (bottom). 
The passing of Agulhas rings in the various models have different signatures in temperature and salinity. The effect on the integration area of the AL will become important when calculating AL transport, because in AGUa0.10 there is no ring signature in temperature and salinity so the integration domain will underestimate the input of rings on velocity and hence the mean transport.

\subsubsection{Mean Agulhas Leakage Volume Transport}

By integrating the velocities across the area defined by the temperature and salinity thresholds [Table 3.2 the AL transport can be calculated [Table 4.1]. ORCA12 has less than half the mean transport of AGUa0.10 and is much lower than expected. AGUa0.10 is the highest and most similar to the estimates from literature and Lagrangian estimates of 10-20 Sv [Speich et al., 2001; Doglioli et al., 2008; Richardson et al., 2007]. The total mean transports are large, with ARC112i more than twice that of the estimates from literature. As the total transport integrates only over positive velocities, these values represent the high velocities associated with one side of the ring which is compensated for by the return flow of the ring in net. Hence, ARC112i has the strongest ring velocities. The difference in means is most likely due to a difference in atmospheric forcings and model domains, which is to be expected.

TABLE 4.1: Model estimates of AL using the adjusted thresholds from van Sebille

\begin{tabular}{c|c|c}
\multicolumn{3}{c}{ including bias from Table 3.2} \\
Model & Transport Type & Mean $(\mathbf{S v})$ \\
\hline ORCA12 & NET & 6.2 \\
\hline & TOTAL & 22.4 \\
\hline AGUa0.10 & NET & 12.8 \\
\hline & TOTAL & 29.3 \\
\hline ARC112i & NET & 11.2 \\
\hline & TOTAL & 46.0 \\
\hline
\end{tabular}

We have validated that the simulations are able to realistically reproduce the structure of the GH line and estimate the mean leakage. But what about the mechanisms of 
variability of the AL? Do the simulations agree on the main drivers of spatio-temporal variability? First we look at spatial variability across the whole GH line.

\subsection{Spatial Variability of The Agulhas Leakage}

The Agulhas system and AL is highly complex with multiple drivers of variability. One of the main challenges for numerical models is realistically replicating the complex dynamics of the regions where variability is both temporal and spatial. To investigate the spatial variability of the complete section two diagnostics are used: Hovmoller diagrams and spatial spectral analysis. The Hovmoller diagram shows at each time step [i] the transport through the GH line, accumulated from the coast offshore over the AL integration domain, [ii] the offshore extent of the AL integration domain as well as [iii] the major paths of rings and their contribution to the total transport. The spatial spectra were computed from surface velocities across the entire GH line for each model. All three spatial spectra have dominant peaks at scales smaller than 50-100km that are likely due to the step structure used in the PAGO extraction, i.e. a feature of the method rather than true variability within the data [Figure 4.7]. This was confirmed by computing the spatial spectrum for one meridional (ccm) and one zonal (ccz) straight line across the Cape Basin in ORCA12 (dotted and dashed lined in Figure 4.6). In those sections, there are no peaks at scales smaller than $100 \mathrm{~km}$ which confirms that this signal along the GH line comes from the stair-cases of PAGO. This however does mean that length scales smaller than $100 \mathrm{~km}$ are not well resolved in the outputs. Moreover, this means if the resolution of the models is high enough to resolve the submesoscale, it will be neglected.

The dominant length scale of ORCA12 occurs where there is a change of slope in the spectra, at 300-400km [Figure 4.7 (top)]. In the Hovmoller diagram the transport anomalies also have an average length of around 300-400km [Figure 4.8 (top)]. This dominant length scale of variability is associated close to the average diameter of Agulhas rings that pass through the section. Comparing the ORCA12 spectra at the GH line to the ccm and ccz lines, shows that the dominant spatial scale for $\mathrm{ccm}$ and $\mathrm{ccz}$ is at smaller 
wavelengths than for the GH line. Hence the GH line is appropriate for the signature of Agulhas rings. Rather, the change in slope seen by the ccm and ccz lines can be related to the local Rossby radius of deformation, slightly smaller than the length scale of Agulhas rings. SSH observations identify rings following three paths as described by Dencausse et al. (2010). The spatial characteristics of the rings are similar in all models, with dominant features having an average diameter of $300-400 \mathrm{~km}$. The pathways of the anomalies passing through the sections however seem to depend on the model. The Hovmoller diagrams show the variability in offshore extent. However, the total transport does not vary significantly with time [Figure 4.8]. There seems to be two paths of rings with the dominant path at 600-700km offshore. Both the time series and Hovmoller show that the transport never reaches zero, meaning that even when there is no ring present there is some form of leakage still occurring, possibly through the submesoscale filaments and jets, although these are of too finer scale to be resolved by these diagnostics. 

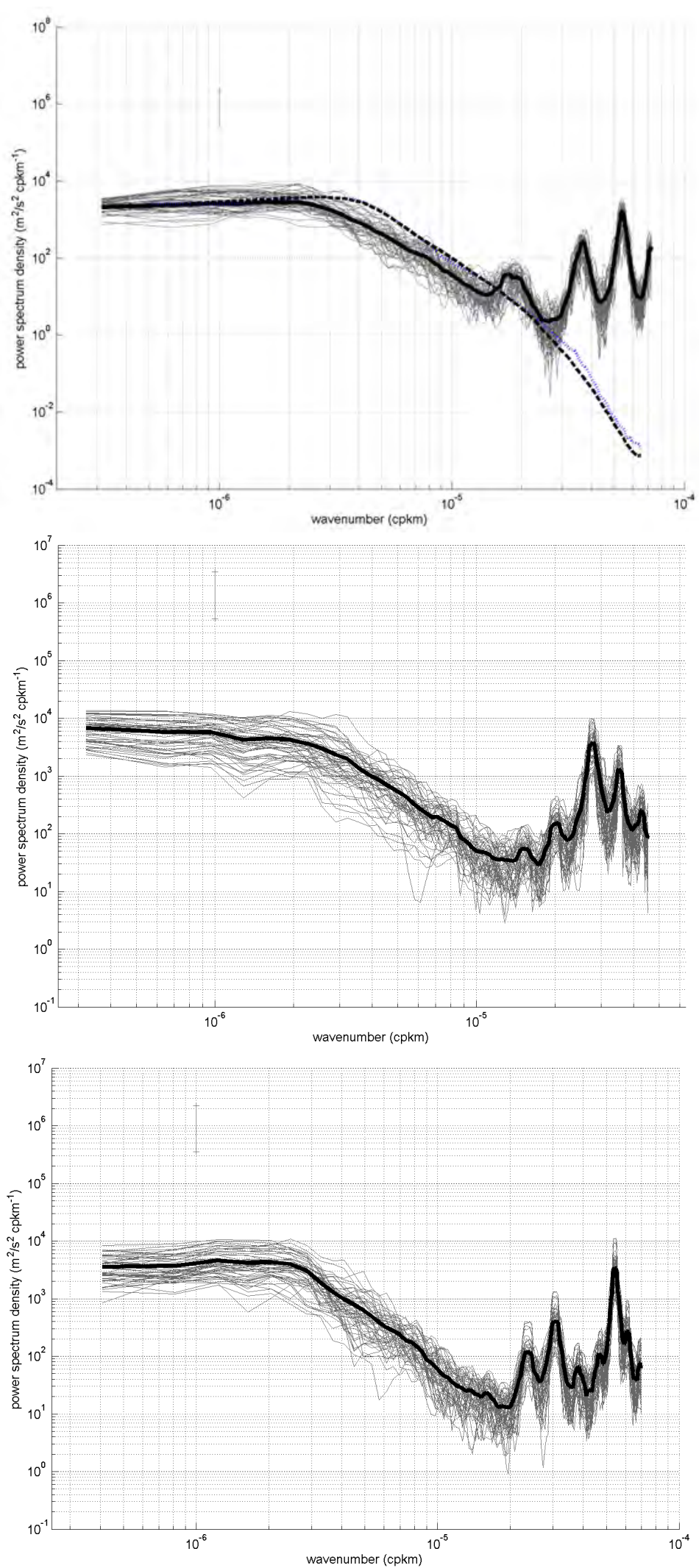

Figure 4.7: ORCA12 (top), AGUa0.10 (middle), ARC112i (bottom) spatial spectra of velocity across GH line. Grey lines represent spectra for each time step and the thick black line is the average of all spectras. In the top panel the dotted line represents sprectras preformed on a meriodional straight line across the Cape Basin and the dashed a zonal line. 

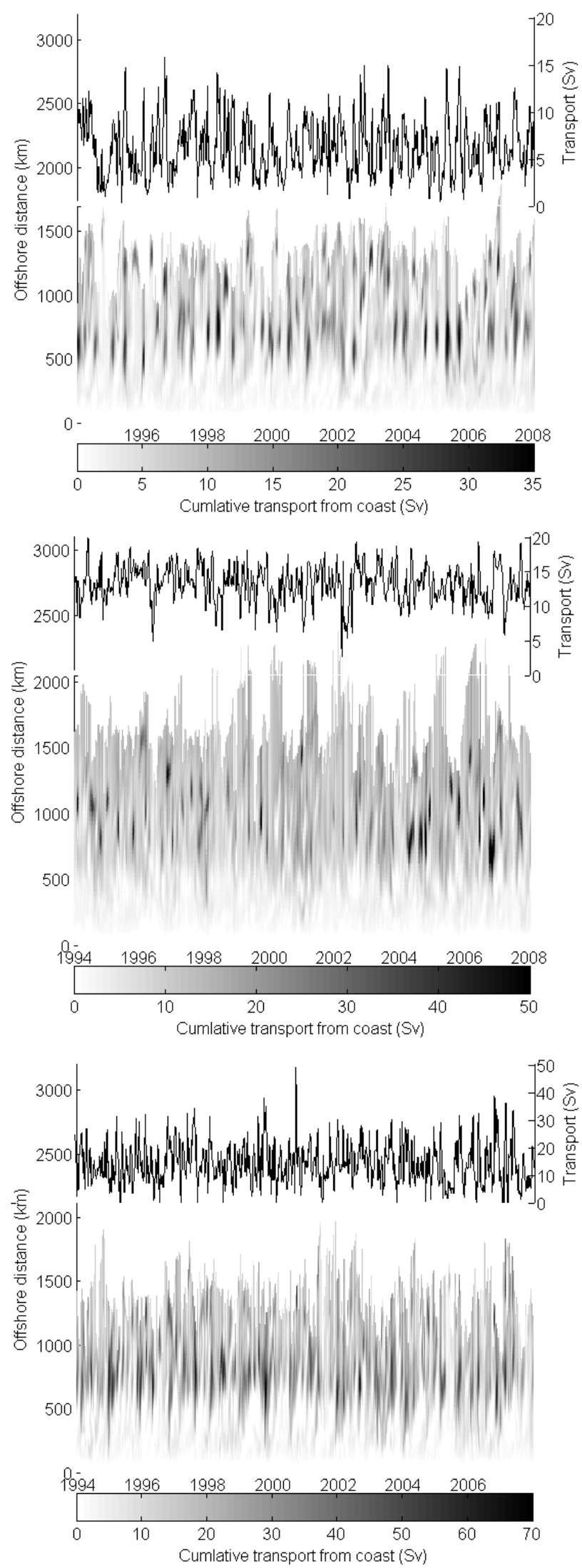

Figure 4.8: Time series and Hovmoller plot of cumulated transport from the coast offshore of the AL. The common time period from 1994-2008 has been chosen for comparison. Top: ORCA12, right: AGUa0.10, bottom: ARC112i 


\subsection{Temporal Variability of the Agulhas Leakage}

The geographic and spatial variability identifies that the simulations are able to generate Agulhas rings with the similar spatial scales and variable pathways. Next we explore further the characteristics of temporal variability in each simulation, starting with seasonality.

\subsubsection{Seasonality}

The AL is expected to be driven by the $\mathrm{AC}$ and thus would be assumed to display a similar seasonal signal as that seen in the AC [Krug and Tournadre, 2012]. However this is not the case. From Figure 4.8 it is seen that even though the offshore extent of the AL displays a relatively large seasonality, as expected from the seasonal migration of isotherms in the meridional direction, the cumulative transport through the section does not display much if any seasonal variability. This is confirmed by the ratios of variance shown in Table 4.2. Indeed, the AL transports (both net and total) are correlated to the depth of the integration area rather than the offshore extent. Still, in ORCA12 and ARC112i the total transport (which includes all the contribution from the Agulhas rings) is highly correlated with the area selected by the thresholds [Figure 4.9]. This reflects the influence of rings on the temperature and salinity fields and hence on the area where the velocities are integrated. Equally when there are no rings crossing the section, the area of integration is reduced and the transport is smaller. As the area displays little seasonality there is similarly no seasonality in the transport. The variability in transport is thus driven by the change in area rather than the offshore extent. In contrast, the area and total transport are not correlated in AGUa0.10. This is likely due to the lack of ring signature on the thermohaline structure as seen in Figure 4.5 (middle).

The seasonal ratios show that the net and total transports have the greatest seasonality in ARC112i [Table 4.2. None of the models display much seasonality within the AL transports, hence the lack of seasonality of the AL seems a robust result beyond model specificities, and in spite of seasonality in the offshore extent of the AL area. We also 
note that ORCA12 and AGUa0.10 have similar standard deviation (std), although the mean magnitude of the leakage is different. ARC112i shows an elevated std which is seen in Figure 4.8 (bottom) reflecting a higher level of high frequency variability, which can be seen as noise.
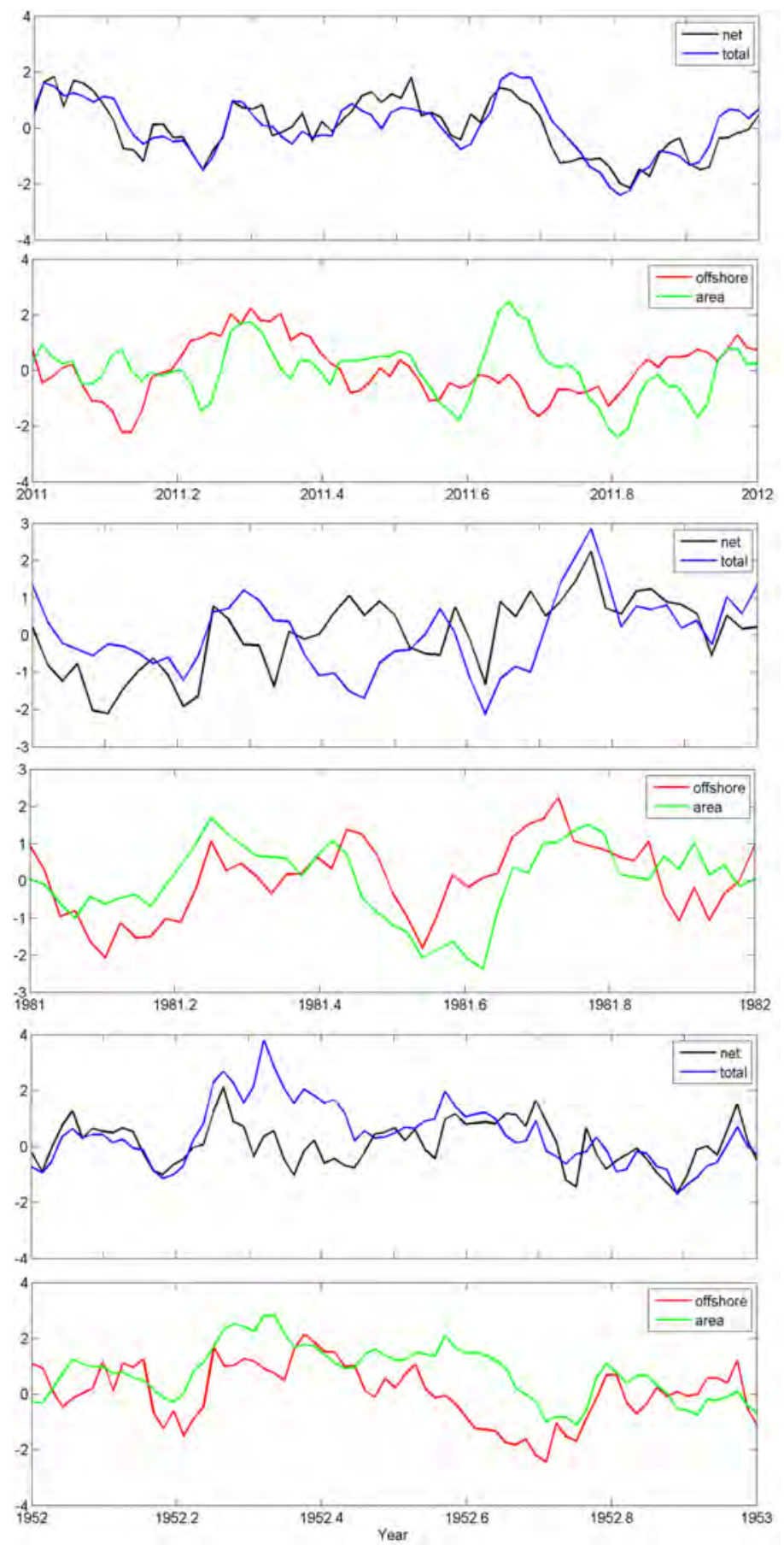

FIGURE 4.9: ORCA12, AGUa0.10, ARC112i normalised seasonal cycle of total, net, area and offshore extent. The highest correlation between cycles occurs for area and total transports by $0.89,0.46$ and 0.80 for ORCA12, AGUa0.10 and ARC112i respectively. 
TABLE 4.2: Ratios of variance of [i] seasonal cycle and [ii] anomalies from the seasonal cycle, over the total variance of NET and TOTAL AL transport, for each model (in \%) with the standard deviation for the full time series (in Sv).

\begin{tabular}{c|c|c|c|c} 
Model & Time series & Seasonal/overall & no seasonal/overall & STD (Sv) \\
\hline ORCA12 & NET & 5.2 & 94.8 & 3.0 \\
\hline & TOTAL & 3.8 & 96.2 & 10.9 \\
\hline AGUa0.10 & NET & 2.4 & 97.6 & 3.5 \\
\hline & TOTAL & 2.2 & 97.8 & 10.5 \\
\hline ARC112i & NET & 13.3 & 86.7 & 6.6 \\
\hline & TOTAL & 15.7 & 84.3 & 19.5 \\
\hline
\end{tabular}

\subsubsection{Interannual Variability}

According to previous studies using satellite observations, Agulhas rings are dispatched from the retroflection at a rate of 5-6 per year [Schouten et al., 2000; Van Aken et al., 2003; Doglioli et al., 2007] and are the dominant form of AL transport. By using spectral analysis, here we assess the dominant mode of temporal variability of the AL in the 3 simulations. Both the net and total time series were used to display the difference between the variability of solely the rings (total) and that of the transport through the whole section (net) [Figure 4.10]. In both sets of spectra there is a flattening at low frequencies and a significant change of slope at intermediate frequencies. The dominant time scale of variability in net transport, represented by the change in slope, is then 3-4 cycles per year (cpy) for ORCA12, 4 cpy for AGUa0.10 and 3-4 cpy for ARC112i. These time scales relate to the frequency of rings that pass through the section and are the same for the total transport spectra. This frequency can also be seen in the time series and Hovmoller diagrams [Figure 4.8]. As seen by the std values ORCA12 and AGUa0.10 display a similar amplitude of variability, while ARC112i displays more noise in particular at intermediate and high frequencies. There is a difference between net transport and total transport in all three models, with total having a much steeper change in slope than net. This is the signature of the mesoscale variability as the total transport only includes the positive velocities of the rings. 

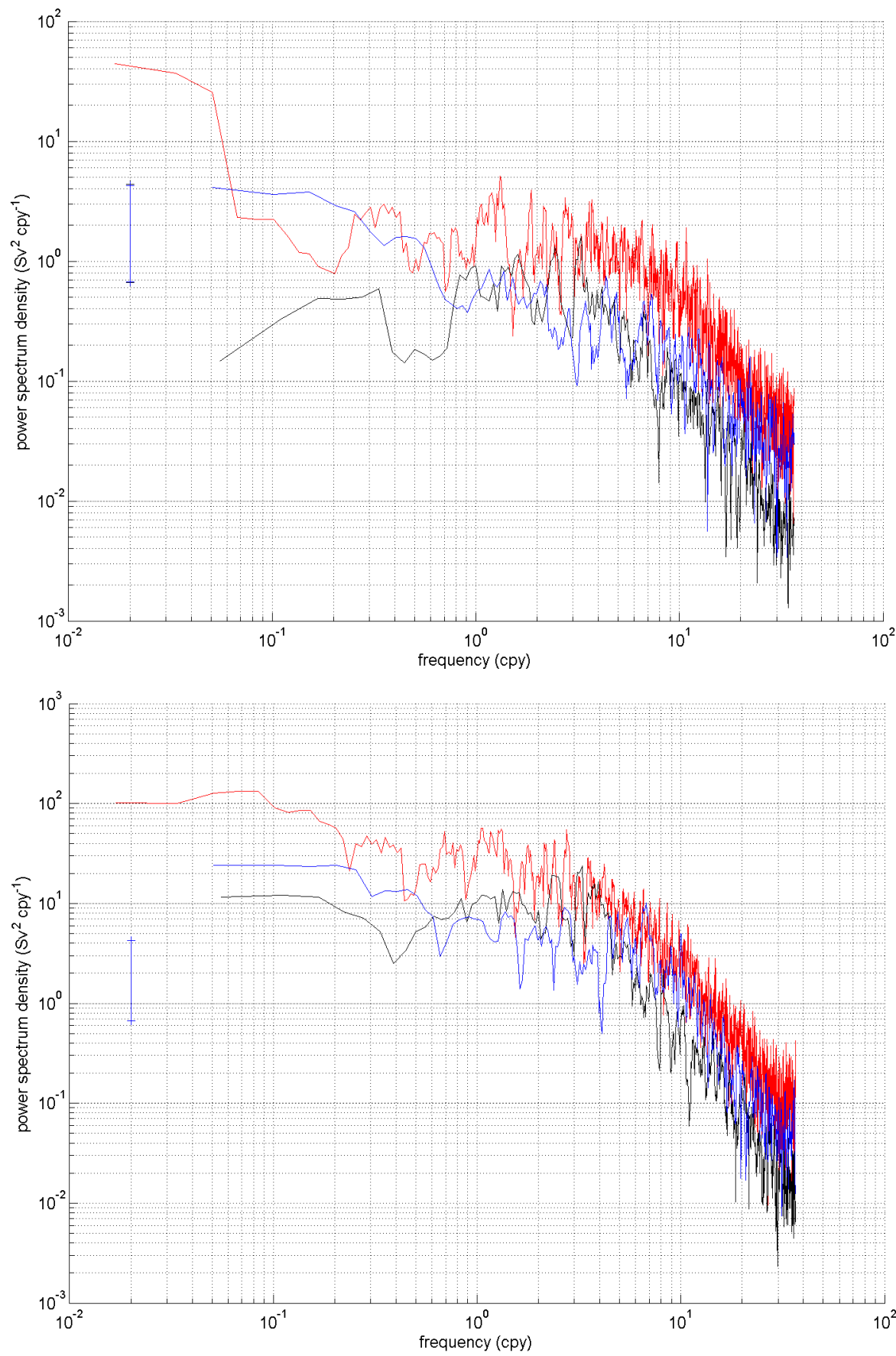

FIGURE 4.10: Time spectral analysis of the net (top) and total (bottom) transports for the three model outputs (ORCA12 is the black line, AGUa0.10 is the blue line and ARC112i the red line). The change in slope identifies the dominant time scale of variability.

In net transport, however, the majority of the cyclic ring velocities cancel out, leaving a smaller residual. The change in slope in AGUa0.10 net transport is more gentle than those of ARC112i and ORCA12, whereas AGUa0.10 total transport has a clear change in slope. This identifies that the total transport reflects a predominant time scale of 
variability ( 5 cpy) which is absent in the net spectra. Although there is a signature in velocity and sea surface height, AGUa0.10 does not generate eddies that affect the stratification and water mass structure of the section. There is little correlation between the velocity and the temperature and salinity profiles, whilst correlation is strong for both ORCA12 and ARC112i. Even if Agulhas rings are present in AGUa0.10, they have a small impact on the transport due to the lack of signature in temperature and salinity hence the temporal spectra of the net transport presents no clear change in slope.

\subsection{Effect of Model Resolution}

As the predominant variability of the AL in high resolution regional hindcasts has been identified to be due to Agulhas rings and these are not assumed to be resolved by coarse resolution models, it is of interest to investigate the mechanism of variability of the AL in lower resolution simulations. The same method used for the high resolution simulations was implemented on the coarse resolution outputs with the adapted temperature and salinity thresholds used [Table 3.2].

TABLE 4.3: Coarse resolution model estimates of AL using the adjusted thresholds from van Sebille (Table 3.2 )

\begin{tabular}{c|c|c|c} 
Model & Transport Type & Mean $(\mathbf{S v})$ & STD $(\mathbf{S v})$ \\
\hline INDa0.12 & NET & 16.8 & 7.2 \\
\hline & TOTAL & 43.7 & 15.4 \\
\hline ORCA025 & NET & 9.1 & 3.0 \\
\hline & TOTAL & 29.2 & 15.0 \\
\hline IPSL-CM5 & NET & 2.6 & 0.5 \\
\hline & TOTAL & 2.7 & 0.5 \\
\hline
\end{tabular}

The calculated AL transports are overall higher than those produced by the ORCA12 and AGUa0.10 [Table 4.3], although ORCA025 remains close to ORCA12. IPSL-CM5 has very small transports with little difference between net and total transport and limited variability $(\operatorname{std}=0.5)$. ORCA025 net transport displays the same std as ORCA12 and AGUa0.10 indicating that it is capturing the same amplitude of variability as the high 
resolution hindcasts. INDa0.12 has a higher std (potentially greater noise) and greater mean than the AGUa0.10 simulation.

\subsubsection{Temporal Variability}

The temporal variability was investigated again using spectra and by comparison with those from the high resolution outputs. Both ORCA025 and INDa0.12 have temporal spectra very similar to their high resolution counterparts. The dominant time scale is 3-4 cpy for ORCA025 [Figure 4.11], compatible with the temporal variability of Agulhas rings. Conjointly with the result of spatial variability, it seems that ORCA025 is able to resolve Agulhas rings reasonably well, which agrees with the findings of Barnier et al. [2006]. By contrast it is seen that INDa0.12, like AGUa0.10 has a very weak change of slope in the spectra at 3-4 cpy, even though spatial analysis does not reveal the presence of rings.

It is possible that there are mesoscale structures in the two HYCOM outputs other than Agulhas rings, that create a slightly predominant variability in total transport, but only weakly contribute to net transport, meaning their two branches cancel out each other and only slightly contribute to the net westward transport. Presumably the time scale is the one dictated by the Rossby radius at this latitude. Indeed, the first baroclinic Rossby radius of deformation obtained from Figure 6 of Chelton et al. [1998], gives a radius $[\mathrm{R}]$ of $\approx 32 \mathrm{~km}$ at the $\mathrm{GH}$ line. The wavelength associated with these waves, given by $2 \pi \mathrm{R}$ is $200 \mathrm{~km}$ which is comparable to the wavelength seen in the spatial spectra of the Cape Cauldron [ccm and ccz in Figure 4.8 (top)]. The dominant first baroclinic mode has a westward phase speed given by $\beta \mathrm{R}^{2}$, where $\beta$ is the Coriolis parameter [Pous et al., 2014]. The propagation speed of westward propagating anomalies is approximately 0.24 $\mathrm{ms}^{-1}$. This speed converted to true time period (wavelength/phase speed) equals 106 days or 3.5 months. This is the temporal scale identified by the gentle change in slope of the INDa0.12 and AGUa0.10 simulations. This suggest that this dominant variability may be due to westward propagating Rossby waves crossing the GH line rather than that of Agulhas rings. 

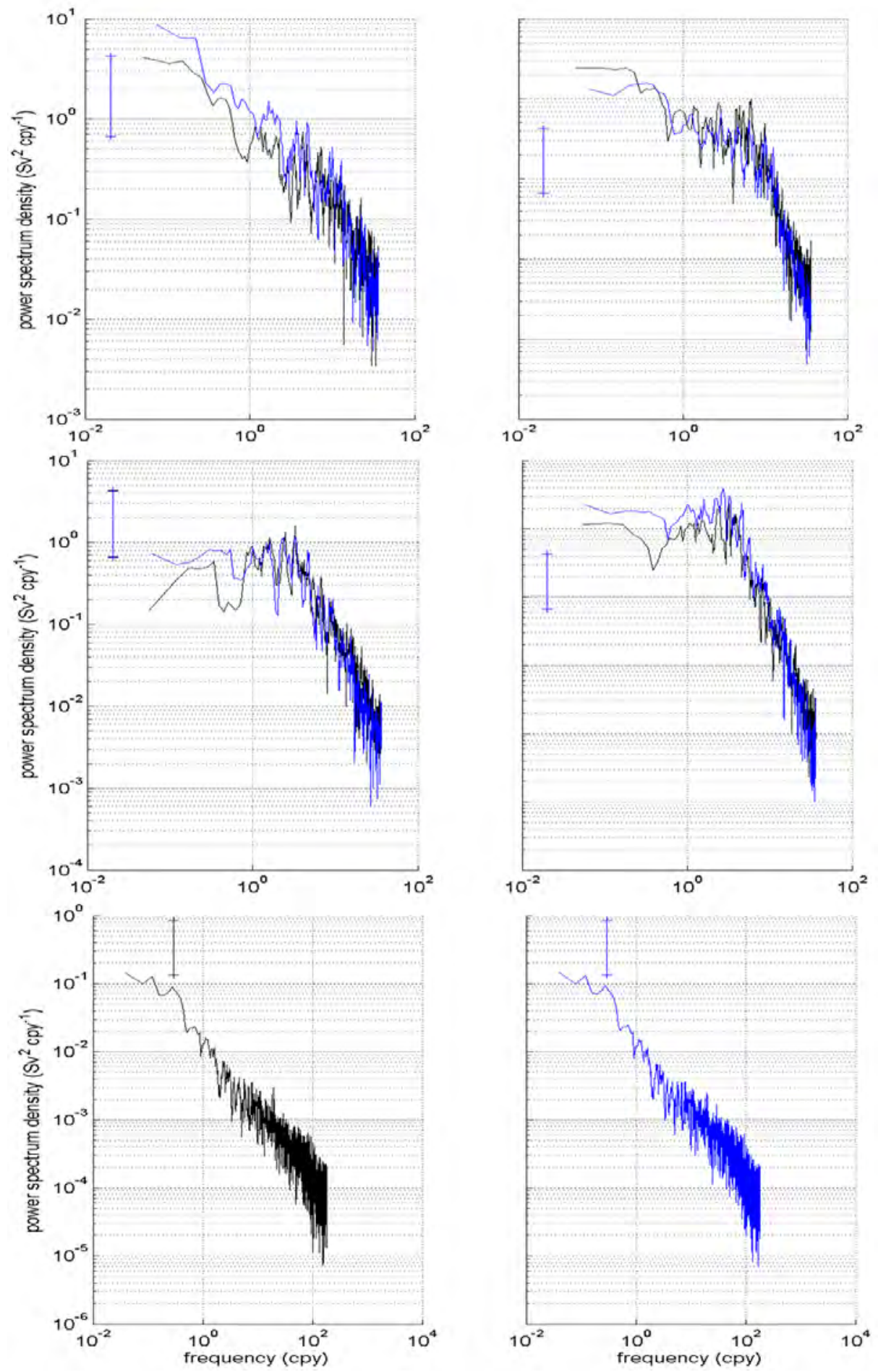

FiguRE 4.11: Spectral analysis of the net (left) and total (right) transports for top: AGUa0.10 (black) and INDa0.12 (blue), middle: ORCA12 (black) and ORCA025 (blue), bottom: IPSL-CM5. The dominant change in slope identifies the dominant time scale of variability

The IPSL-CM5 simulation shows no predominant scale of variability in both net and total transport, hence it most likely does not resolve Agulhas rings. The spectrum is 
similar to that of the large scale open ocean with no specific variability. Hence in this simulation, the Agulhas system is expected to have no influence on the variability of the global circulation of heat and salt, nor on the AMOC and global climate.

\subsubsection{Spatial Variability}

The spatial scale of surface velocity anomalies is estimated using spatial spectra in ORCA025 and INDa0.12, as for the high resolution hindcasts.
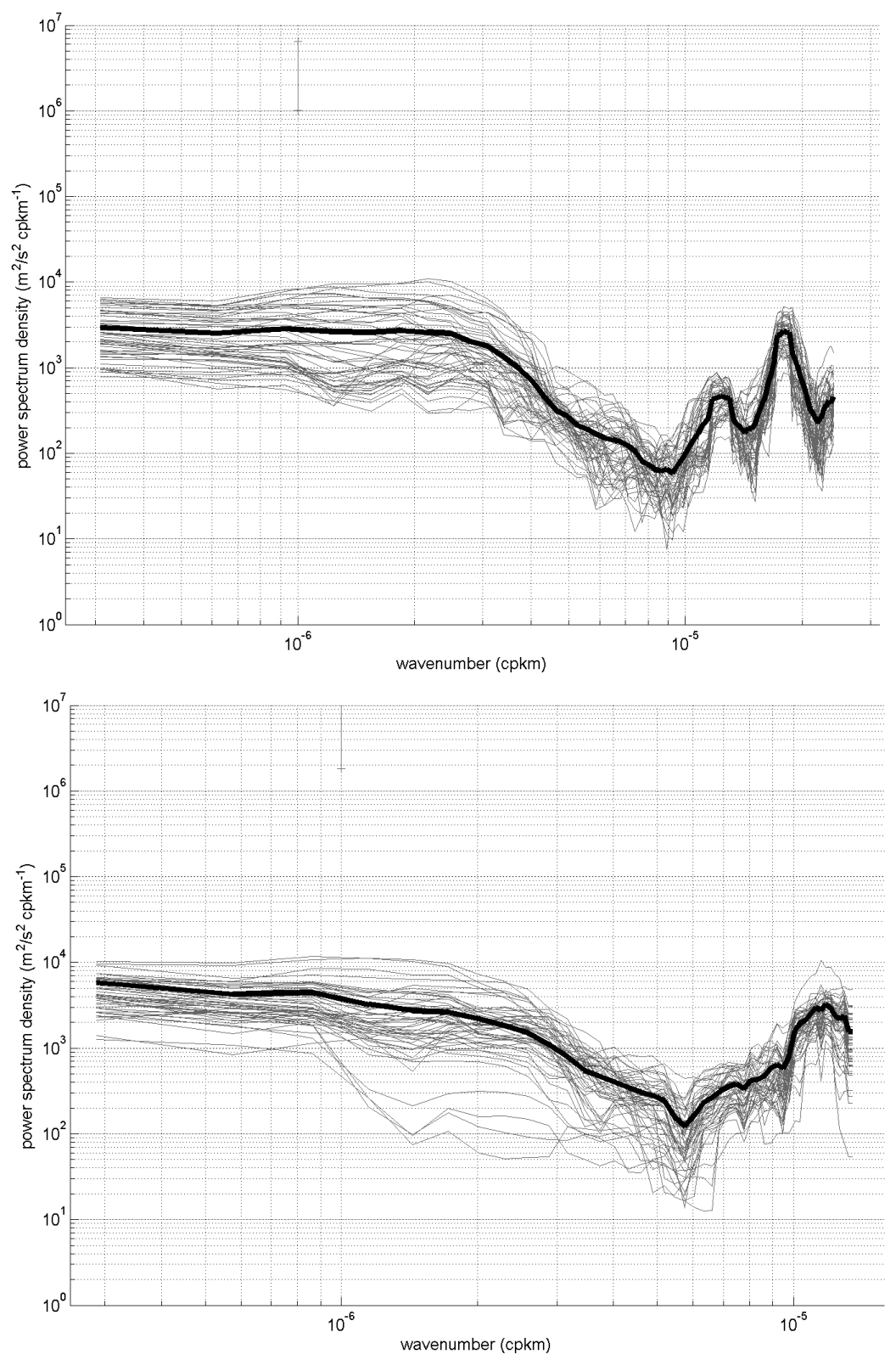

FigURE 4.12: Same as Figure 4.7 for ORCA025 (top) and INDa0.12 (bottom). 
A change in slope occurs at wavelengths of around 300-400 km in ORCA025 [Figure 4.12 (top)], which is consistent with the wavelength of Agulhas rings identified in the hindcasts. The INDa0.12 spectrum shows no dominant wavelength and hence does not appear to resolve Agulhas rings [Figure 4.12 (bottom)]. Hovmoller analysis of the transport through the GH line is only useful for ORCA025. Although the variability in transport and offshore extent is very similar to that of ORCA12, it seems that only one pathway for the Agulhas rings is reproduced [Figure 4.13], as expected from such a coarse resolution simulation (Barnier et al. 2006).

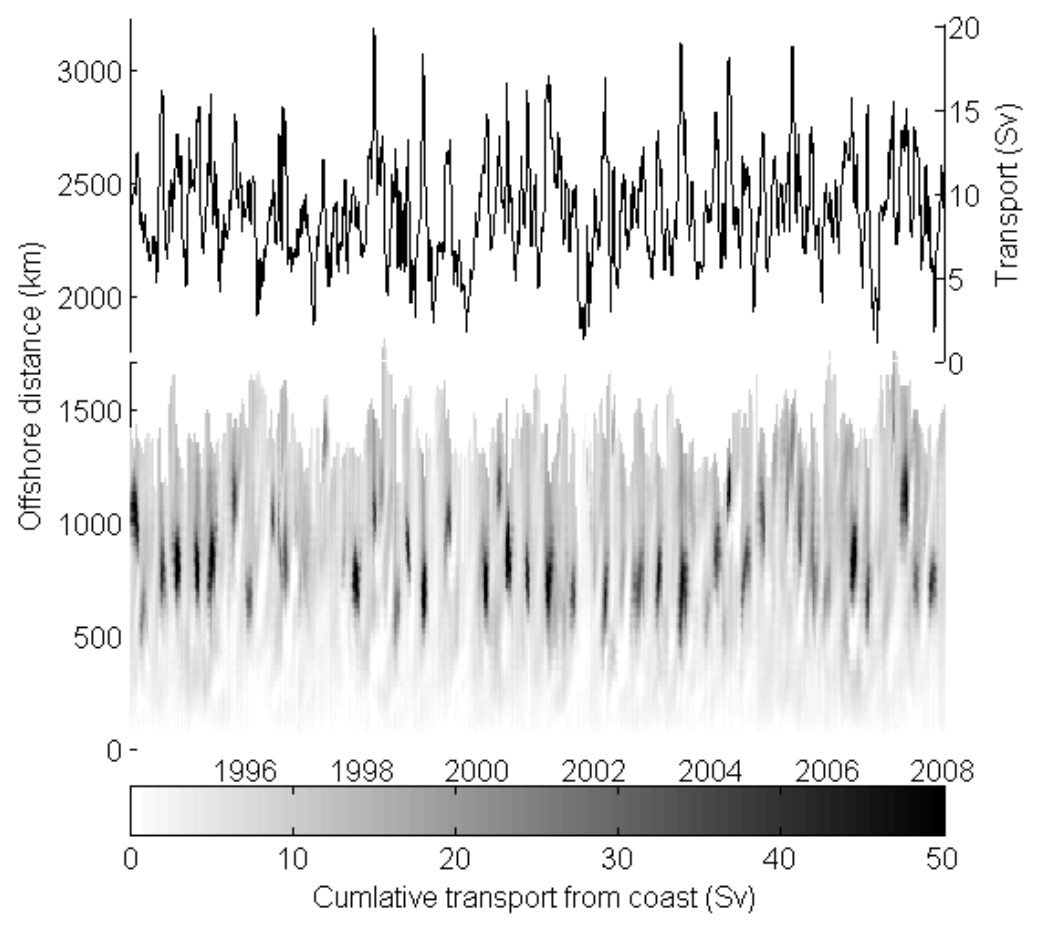

Figure 4.13: Same as Figure 4.8 for ORCA025

\subsection{Summary}

Table 4.4 identifies the key findings of the results described above. It acts as a summary of the models ability to represent the observed variability of the AL. 


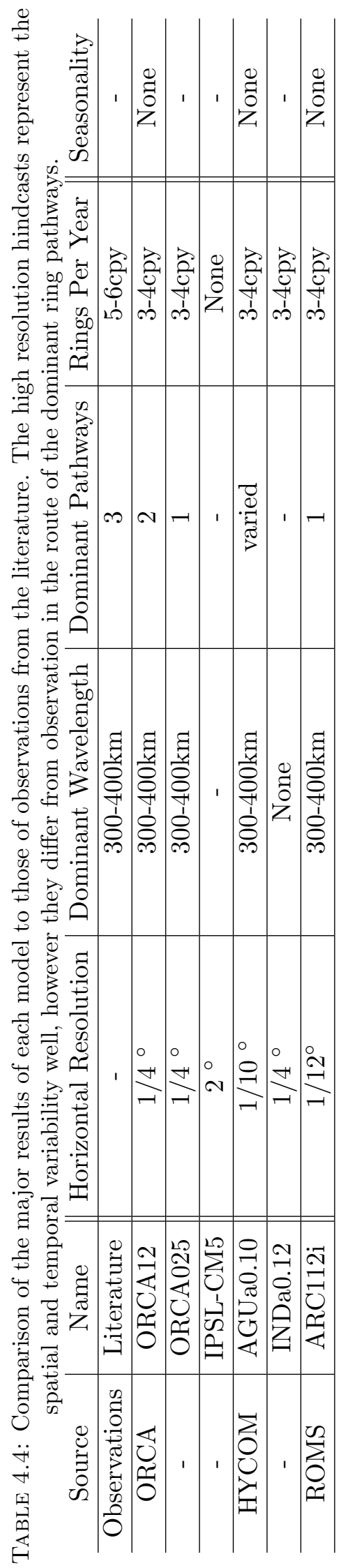





\section{Chapter 5}

\section{Conclusions}

While the separate components of the AL have been widely studied, the variability of the AL has not been investigated. This study introduced a method to inter-compare several model outputs to identify the characteristics of variability in the AL, beyond the model specificities and biases. With limited observational data, the use of numerical models for investigations of the AL is invaluable. The provision of full depth velocity data alone is beyond that of observations. There is no general consensus on the best method to measure AL, with Lagrangian methods being computationally expensive and not easily applied across several models, while Eulerian approaches tend to underestimate the magnitude of the leakage, however capture the variability well [van Sebille et al., 2010; Loveday et al., 2014]. For intercomparison across multiple simulations and as the main interest lies in determining the mechanisms of variability, an Eulerian method was used. After testing three forms of Eulerian method, the use of thermohaline thresholds to integrate velocities to form a volume flux provided the closest estimates, when compared to the actual magnitude of the leakage determined by passive tracers. The implementation of one robust method across multiple models allows for comparison which is difficult when different methods are used. Using the GH line as a well-defined boundary, each simulation can be analysed in the same way. 
The use of high-resolution ocean hindcasts was motivated by the fact that the Agulhas Current, retroflection and rings are properly resolved and should hence represent the variability well. The thermohaline structure of the GH line section is reproduced adequately in the three high resolution hindcast simulations when compared to the observations from the 2008 BONUS-GOODHOPE cruise. The velocity structures identify a dominant positive velocity pathway located at $500 \mathrm{~km}$ offshore that extends to the seafloor in all three models. This mean barotropic current is found to be created by a local feature in the bathymetry. As the Agulhas retroflection is highly nonlinear the estimated mean leakage is highly variable and its mean amplitude depends on the model parameters, lateral boundary conditions and atmospheric forcing datasets. With our method of quantification of the AL, all three models show a non-zero background leakage, even though the mean amplitude and variability of the AL are different. The existence of a background leakage is then robust among high-resolution simulation. Still, its origin remains unclear, as it is presumably due to submesoscale processes but our methodology impedes us from clarifying their impact on the volume transport across the GH line. Besides, van Sebille et al. [2009] concluded that for the purpose of gauging northern Atlantic Ocean climate fluctuations it is the variability more than the mean that is important, hence we focused on the mechanisms of variability in the rest of our study.

The turbulent AC retroflection region forms eddies, rings and filaments which act as vehicles for interocean exchange (Gordon, 2003; Richardson et al., 2003). Dominant temporal variability for all three models is found to be between 3-5 times per year which is comparable to the shedding rate of Agulhas rings from observations [Schouten et al., 2000], this confirms that Agulhas rings are the dominant driver of variability of the AL. Although there is seasonality present in the offshore extent, no seasonality is present within the transport. It would be expected that a movement of the leakage offshore would result in an increase in the transport, however this is not seen. Instead an increase in transport occurs as a response to an increase in the area of the integration domain. Thus transport is sensitive to changes in the vertical depth rather than fluctuations in 
the offshore extent.

We only investigated the temporal variability in the AL volume transport, even though the role that the AL plays in climate is through the flux of heat and salt into the South Atlantic. As changing climate is of utmost relevance, how the mechanisms of variability in the volume transport imprint on the variability of the heat, freshwater and salt transport by the AL is of great interest. The benefit of Eulerian methods is the ability to estimate heat and salt fluxes. To achieve this through the GH line, a reference temperature and salinity is needed for the South Atlantic, which is not straightforward to estimate. Moreover it is already complex to interpret the variability of the volume transport alone, so by introducing another source of variability via temperature, salinity or freshwater, it may be more difficult to conclude on the mechanisms of variability. As a consequence, our analysis of the temporal variability in AL volume transport should be seen as a first step towards clarifying the contribution of the AL to the variability of the global ocean circulation hence climate.

Although all three models converge on the characteristics of temporal variability, they diverge in the spatial characteristics (horizontal and vertical) of the anomalies passing through the sections. The average diameter of rings is $300-400 \mathrm{~km}$ (radius of $150-200 \mathrm{~km}$ ) which agrees with observational studies of Agulhas rings using satellite altimetry [Arhan et al., 1999; van Aken et al., 2003]. The models are therefore realistic in the spatial variability of the AL. The pathways taken by the rings however differ in each model. The literature expresses that a dominant eddy pathway is found $900 \mathrm{~km}$ offshore, located at the position where most floats cross during Lagragrian experiments, which is seen here as the dominant pathway in ARC112i. Topography plays an important role in the drift and evolution of Agulhas rings, with the Agulhas Ridge initially responsible for the splitting and blocking the paths of rings [van Veldhoven et al., 2005]. The pathway of rings is important as decay and transformation rates depend on the direction of travel [Dencausse et al., 2010]. Rings moving to the south are more prone to strong winter cooling, with those moving north into warmer less turbulent regions more likely to retain more of their initial temperature and salinity signature [van Veldhoven et al., 
2005]. As rings are the dominant form of exchange in the context of global circulation and climate, correct reproduction of the pathways of the rings is very important. It is thus very relevant that ocean models are able to represent not only the presence of rings but also the horizontal spatial variability. Although the length scale for AGUa0.10 is similar to that of ORCA12, there are less rings evident in the Hovmoller with a much more variable ring pathway. Moreover, the difference in the net and total transport temporal spectra indicate that the cyclic positive and negative velocities of the mesoscale structures picked up in AGUa0.10 although present strongly in the calculation of the total transport (only positive velocities are integrated), compensate each other almost entirely in the net transport.

The variability of the AL is influenced by the dynamics of the three surrounding circulation systems. The impact of the South Atlantic is most likely through the vigorous mixing of the leakage and decay of rings in the Cape Basin, which the impact on variability is difficult to quantify. The dynamics of the $\mathrm{AC}$ is presumed to have the greatest impact on AL fluctuations through the location of the retroflection and the production of rings. Our methodology to quantify the AL in a robust fashion in different simulations could then be used to test whether the correlation between the AC and the AL depends on the model settings and parameters. Finally, the offshore distance of integration of the AL terminates at the Subtropical Front between the warm, saline waters of the leakage and the cold fresher waters of the Southern Ocean. The position of the Subtropical front is determined by the dynamics of the Southern Ocean. If the Southern Ocean influence on the leakage variability works via the offshore extent, the influence is limited because the correlation between transport and offshore extent is weak and independent of the simulation type.

Even though Agulhas rings are seen here to dominate the spatial and temporal variability in the high resolution models, it must again be stated that they only individually transport volumes of 0.5-1.5 Sv [Schouten et al., 2000]. This brings into context the idea of a background leakage on which the rings are superimposed on top, as the rings alone can not be responsible for the AL transport estimates of 10-20 Sv. At the GH 
line the presence of a warm, saline lens that correlates with the presence of a constant positive velocity and non zero transport, may be the result of the combination of fast decay of rings and vigorous mixing of water masses in the Cape Basin. When the AL is separated into relative components such as rings and filaments, the variability depends on how far from the retroflection the analysis is performed [Doglioli et al., 2006]. It can be said that in this study the choice of location ( $\mathrm{GH}$ line) is important to the results as when performed on a straight line the ring signature is lost.

In the literature, coarse non-eddy resolving ocean models not only underestimate the mean leakage, but also exhibit no interannual variability in the upper circulation. Simulated AL transports have been reported to be sensitive to model resolution [Durgedoo et al., 2013; Loveday et al., 2014] as it depends on the production of Agulhas rings. Both $1 / 4^{\circ}$ eddy permitting coarse resolution models are able to capture some type of mesoscale variability. As was found with AGUa0.10, the coarser resolution INDa0.12 configuration identifies a form of mesoscale variability however does not resolve Agulhas rings. If Agulhas rings are the dominant form of leakage, then INDa0.12 cannot be used to quantify the AL at the GH line. The INDa0.12 simulation identifies the same temporal time scale and difference between net and total transport as AGUa0.10, however the spatial spectra differ. Whilst AGUa0.10 displays a definite dominant length scale, INDa0.12 does not show an obviously dominant length scale. Thus, although AGUa0.10 does not appear to resolve Agulhas rings, it does capture coherent structures with wavelengths of $300 \mathrm{~km}$ which the coarser INDa0.12 output does not.

Although ORCA025 has the ability to resolve Agulhas rings, the Hovmoller in Figure 4.12 shows a dominant ring pathway which from observational evidence is assumed incorrect. This agrees with the findings of Barnier et al. [2006], where they showed that although ORCA025 can resolve rings, the ring pathway is almost held entirely in a single trajectory which is not realistic. This is similar to the high resolution output of ARC112i which although was able to resolve the temporal and spatial scales of the rings well, only identified a singular dominant ring path. It can then be concluded that increasing horizontal resolution is not sufficient to ensure a realistic representation of 
the temporal, spatial variability and pathways of Agulhas rings. Understanding further the characteristics of the eddy structures as represented in the different models would be of interest for a future, more in depth study of the mechanisms of variability of the AL.

In our current changing climate, future predictions are based on coarse resolution noneddy resolving climate models, such as the $2^{\circ}$ IPSL-CM5 which we analysed here. The AL in this simulation shows no predominant scale of variability, rather the spectrum is similar to that of the large scale open ocean with no specific variability related to Agulhas rings. Thus in this simulation we suggest that the Agulhas system has no influence on the variability of the global circulation of heat and salt, hence the AMOC and global climate. 


\section{Chapter 6}

\section{Bibliography}

Ansorge, I.J., Speich, S., Lutjeharms, J.R.E., Goni, G.J., Rautenbach, C.J., Froneman, P.W., Rouault, M. and Garzoli, S.L., 2005. Monitoring the oceanic flow between Africa and Antarctica: report of the first Good Hope cruise. S.African J.Sci. 101, 2935.

Backeberg, B.C., Bertino, L., and Johannessen, J., 2009. Evaluating two numerical advection schemes in HYCOM for eddy-resolving modelling of the Agulhas Current. Ocean Sci., 5, 173190, doi:10.5194/os-5-173-2009.

Backeberg, B.C. and Reason C.J.C., 2010. A connection between the South Equatorial Current north of Madagascar and Mozambique Channel eddies. Geophys. Res. Lett., 37, L04604, doi:10.1029/2009GL041950.

Backeberg, B.C., Penven, P. and Rouault, M., 2012. Impact of intensified Indian Ocean winds on mesoscale variability in the Agulhas system. Nat. Climate Change, 2, 608612, doi:10.1038/nclimate1587.

Backeberg, B.C., Counillon, F., Johannessen, J.A. and Pujol, M.I., 2014. Assimilating along-track SLA data using the EnO1 in an eddy resolving model of the Agulhas system. Ocean Dynamics, 64 (8), 1121-1136, doi:10.1007/s10236=014-0717-6.

Barnier, B., Madec, G., Penduff, T., Molines, J-M., Treguier, A-M., Le Sommer, J., Beckmann, A., Boning, C., Dengg, J., Derval, C., Durand, E., Gulev, S., Remy, E., Talandier, C., Theerren, S., Maltrud, M., McClean, J. and de Cuevas, B., 2006. Impact of partial steps and momentum advection schemes in a global ocean circulation model at 
eddy-permitting resolution. Ocean Dynamics, 56, (5-6), 543-567. (doi:10.1007/s10236006-0082-1).

Beal, L.M. and Bryden, H.L., 1999. The velocity and vorticity structure of the Agulhas Current at 32 S. Journal of Geophysical Research. 104, 51515176.

Beal, L.M., de Ruijter, W.P.M., Biastoch, A., Zahn, R. and SCOR/WCRP/IAPSO Working Group 136, 2011. On the role of the Agulhas system in ocean circulation and climate. Nature, 472, 429436, doi:10.1038/nature09983.

Biastoch, A., Beal, L.M., Lutjeharms, J.R.E. and Casal, T.G.D., 2009a. Variability and coherence of the Agulhas Undercurrent in a high-resolution ocean general circulation model. J.Phys.Oceanogr. 39, 24172435.

Biastoch, A., Boning, C.W., Schwarzkopf, F.U. and Lutjeharms, J.R.E., 2009b. Increase in Agulhas leakage due to poleward shift of Southern Hemisphere westerlies. Nature. 462, 495499.

Biastoch, A., Boning, C.W., Getzlaff, J., Molines, J.M. and Madec, G., 2008a. Causes of interannual-decadal variability in the Meridional Overturning Circulation of the mid latitude North Atlantic Ocean. J.Clim. 21, 65996615.

Biastoch, A., Boning, C.W. and Lutjeharms, J.R.E., 2008b. Agulhas leakage dynamics affects decadal variability in Atlantic overturning circulation. Nature. 456, 489492.

Biastoch, A., Lutjeharms, J.R.E., Boning, C.W. and Scheinert, M., 2008c. Mesoscale perturbations control inter-ocean exchange south of Africa. Geophys.Res.Lett. 35, L20602.

Blanke, B. and Delecluse, P., 199.: Variability of the Tropical Atlantic Ocean simulated by a general circulation model with two different mixed-layer physics. J. Phys. Oceanogr. 23, 1363-1388.

Bleck, R., 2002. An oceanic general circulation model framed in hybrid isopycnicCartesian coordinates. Ocean Model, 37, 5588 
Boebel, O., Lutjeharms, J.R.E., Schmid, C., Zenk, W., Rossby, T. and Barron, C., 2003a. The Cape Cauldron: a regime of turbulent inter-ocean exchange, Deep-Sea Res. 50, $57-86$.

Bryden, H., Beal, L. and Duncan, L., 2005. Structure and transport of the Agulhas Current and its temporal variability. J. Oceanogr., 61, 479492, doi:10.1007/s10872-0050057-8.

Caley, T., Peeters, F.J.C., Biastoch, A., Rossignol, L., van Sebille, E., Durgadoo, J., Malaize, B., Giraudeau, J., Arthur, K. and Zahn, R., 2014. Quantitative estimate of paleo-Agulhas leakage. Geophys. Res. Lett. 41. 1238-1246, doi:10.1002/2014GL059278

Dencausse, G., Arhan, M. and Speich, S., 2010a. Spatio-temporal characteristics of the Agulhas Current retroflection. Deep Sea Res. 57. 1392-1405.

Dencausse, G., Arhan, M. and Speich, S., 2010b. Routes of Agulhas rings in the southeastern Cape Basin. Deep Sea Res. 57. 1406-1421.

de Ruijter, W., 1982. Asymptotic analysis of the Agulhas and Brazil Current systems. J. Phys. Oceanogr., 12, 361373, doi:10.1175/1520-0485(1982)012,0361:AAOTAA.2.0.CO;2.

de Ruijter, W., and Boudra, D., 1985. The wind-driven circulation in the South AtlanticIndian Ocean. Numerical experiments in a one-layer model. Deep-Sea Res. I, 32, 557574, doi:10.1016/0198-0149(85)90044-5.

de Ruijter, W., A. Biastoch, S. Drijfhout, J. Lutjeharms, R. Matano, T. Pichevin, P. van Leeuwen, and Weijer, W., 1999. IndianAtlantic interocean exchange: Dynamics, estimation and impact. J. Geophys. Res., 104, 2088520 910, doi:10.1029/1998JC900099.

de Ruijter, W., H. Aken, E. Beier, J. Lutjeharms, R. Matano, and Schouten, M., 2004. Eddies and dipoles around south Madagascar: Formation, pathways and large-scale impact. Deep-Sea Res. I, 51, 383400, doi:10.1016/j.dsr.2003.10.011.

Deshayes, J., Treguier, A.M., Barnier, B., Lecointre, A., Le Sommer, J., Molines, J.M., Penduff, T., Bourdalle-Badie, R., Drillet, Y., Garric, G., Benshila, R., Madec, G., Biastoch, A., Boning, C. W., Scheinert, M., Coward, A.C. and Hirschi, J.J., 2013. Oceanic 
hindcast simulations at high resolution suggest that the Atlantic MOC is bistable, Geophys. Res. Lett., 40, 3069-3073 doi:10.1002/grl.50534.

Dijkstra, H. and de Ruijter, W.P.M., 2001. On the physics of the Agulhas Current: Steady retroflection regimes. J. Phys. Oceanogr., 31, 29712985, doi10.1175/15200485(2001)031,2971: OTPOTA.2.0.CO;2.

Doglioli, A.M., Veneziani, M., Blanke, B., Speich, S. and Griffa, A., 2006. A Lagrangian analysis of the IndianAtlantic interocean exchange in a regional model. Geophysical Research Letters. 33, L14611.

Donners, J. and Drijfhout, S.S., 2004. The Lagrangian view of South Atlantic interocean exchange in a global ocean model compared with inverse model results. J. Phys. Oceanogr. 34, 10191035.

Durgadoo, J.V., Loveday, B.R., Reason, C.J., Penven, P. and Biastoch, A., 2013. Agulhas Leakage Predominantly Responds to the Southern Hemisphere Westerlies, J. Phys. Oceanogr., 43, 21132131.

Dufresne J-L., Foujols M-A., Denvil S., Caubel A., Marti O., Aumont Olivier, Balkanski Y., Bekki S., Bellenger H., Benshila R., Bony S., Bopp L., Braconnot P., Brockmann P., Cadule P., Cheruy F., Codron F., Cozic A, Cugnet D., De Noblet N., Duvel JP., Ethe, Fairhead L., Fichefet T., Flavoni S., Friedlingstein P., Grandpeix J-Y., Guez L., Guilyardi E., Hauglustaine D., Hourdin F., Idelkadi A., Ghattas J., Joussaume S., Kageyama M., Krinner G., Labetoulle S., Lahellec A., Lefebvre M, Lefevre F., Levy C., Li Zhanbin, Lloyd J., Lott F., Madec G., Mancip M., Marchand M, Masson S., Meurdesoif Y., Mignot J., Musat I., Parouty S., Polcher J., Rio C, Schulz M., Swingedouw D., Szopa S., Talandier Claude, Terray P., Viovy N. and Vuichard N., 2013. Climate change projections using the IPSL-CM5 Earth System Model: from CMIP3 to CMIP5. Climate Dynamics, 40(9-10), 2123-2165.

Fichefet, T. and Morales Maqueda, M.A., 1997. Sensitivity of a global sea ice model to the treatment of ice thermodynamics and dynamics. J. Geophys. Res., 102, 1260912646.

Goni, G.J., Garzoli, S.L., Roubicek, A.J.,Olson, D.B. and Brown, O.B., 1997. Agulhas ring dynamics from TOPEX/POSEIDON satellite altimeter data. Journal of Marine 
Research, 55(5): 861-883.

Gordon, A.L., 1986. Interocean exchange of thermocline water. J. Geophys. Res., 91 (C4), 50375046 .

Gordon, A.L., R.F. Weiss, W.M. Smethie, and Warner, M.J., 1992. Thermocline and intermediate water communication between the South Atlantic and Indian Oceans. $J$. Geophys. Res., 97, 72237240.

Hermes, J.C., Reason, C.J.C. and Lutjeharms, J.R.E., 2007. Modeling the variability of the Greater Agulhas Current System. J.Clim. 20, 31313146.

Krug, M., and Tournadre, J., 2012. Satellite observations of an annual cycle in the Agulhas Current, Geophys. Res. Lett., 39, L15607, doi:10.1029/2012GL052335.

Le Bars, D., W.P.M. de Ruijter, and Dijkstra, H.A., 2012. A new regime of the Agulhas Current retroflection: Turbulent choking of IndianAtlantic leakage. J. Phys. Oceanogr., 42, 11581172 .

Le Sommer, J., Penduff, T., Theetten, S., Madec, G. and Barnier, B., 2009. How momentum advection schemes influence current-topography interactions at eddy-permitting resolution. Ocean Model. 29, 1-14.

Loveday, B.R., Durgadoo, J.V., Reason, C.J.C., Biastoch, A. and Penven, P., 2013. Decoupling of the Agulhas Leakage from the Agulhas Current. J. Phys. Oceanogr. 44, 1776-1797.

Lutjeharms, J.R.E. and Cooper, J., 1996. Interbasin leakage through Agulhas current filaments. Deep Sea Res., Part I 43, 213238.

Madec, G., 2008. NEMO ocean engine. Note du Pole de Modelisation de linstitut Pierre-Simon Laplace 27, 215 pp

Madec, G. and Imbard, M., 1996. A global ocean mesh to overcome the North Pole singularity. Climate Dyn., 12, 381388, doi:10.1007/BF00211684. 
Marchesiello, P., McWilliams, J.C. and Shchepetkin. A.F., 2003. Equilibrium structure and dynamics of the California Current System, J. Phys. Oceanogr., 33, 753-783.

Matano, R.P. and Beier, E.J., 2003. A kinematic analysis of the Indian/Atlantic interocean exchange. Deep-SeaRes. II50, 229250.

Mercier, H., Arhan, M., Lutjeharms, J.R.E., 2003. Upper-layer circulation in the eastern equatorial and South Atlantic Ocean in JanuaryMarch 1995. Deep-Sea Research I. 50, 863887.

Peeters, F.J.C., Acheson, R., Brummer, G.J.A., de Ruijter, W.P.M, Schneider, R. R., Ganssen, G.M., Ufkes, E. and Kroon , D., 2004. Vigorous exchange between the Indian and Atlantic oceans at the end of the past five glacial periods. Nature. 430, 661-665.

Penven, P., Chang, N. and Shillington, F., 2006a. Modelling the Agulhas Current using SAfE (Southern Africa Experiment). Geophysical Research Abstracts, 8, Abstract 04225.

Penven, P., Roy, C., Brundrit, G.B., Colin de Verdiere, A., Freon, P., Johnson, A.S., Lutjeharms J.R.E. and Shillington, F., 2001. A regional hydrodynamic model of upwelling in the Southern Benguela, South African Journal of Science, 97, 472-475.

Reason, C.J.C., Lutjeharms, J.R.E., Hermes, J., Biastoch, A. and Roman,R.E., 2003. Inter-ocean fluxes south of Africa in an eddy-permitting model. Deep-SeaRes. II50, 281298 .

Richardson, P. L., 2007. Agulhas leakage into the Atlantic estimated with subsurface floats and surface drifters. Deep-Sea Res. I, 54, 13611389, doi:10.1016/j.dsr.2007.04.010.

Richardson, P.L., Lutjeharms, J.R.E. and Boebel, O., 2003. Introduction to the "Interocean exchange around southern Arfica", Deep Sea Res., 50 (1), 1-12.

Rouault, M., Penven, P. Pohl, B. 2009: Warming in the Agulhas Current systemsince the 1980s. Geophys. Res. Lett. 36, L12602. 
Rhs, S., Durgadoo, J.V., Behrens, E. and Biastoch, A., 2013. Advective timescales and pathways of Agulhas leakage, Geophys. Res. Lett., 40, 39974000, doi:10.1002/grl.50782.

Ruijter, W.P.M., 2006. Observations of the Inter-Ocean Exchange Around South Africa. EOS. 87 (9). 97-101.

Schmitz Jr, W.J., 1995. On the interbasin-scale thermohaline circulation.Rev.Geophys. 33, 151173.

Schouten, M.W., DeRuijter, W.P.M., VanLeeuwen, P.J. and Lutjeharms, J.R.E., 2000. Translation, decay and splitting of Agulhas rings in the southeastern Atlantic Ocean. J.Geophys.Res. 105, 2191321925.

Schouten, M., de Ruijter, W. and van Leeuwin, P., 2002. Upstream control of Agulhas ring shedding. J. Geophys. Res., 107, 3109, doi:10.1029/2001JC000804.

Speich, S., Blanke, B., and Madec, G., 2001. Warm and cold water routes of an OGCM thermohaline conveyor belt. Geophys. Res. Lett., 28, 311314, doi:10.1029/2000GL011748.

Speich, S., Lutjeharms, J.R.E., Penven, P. and Blanke, B., 2006. Role of bathymetry in Agulhas Current configuration and behaviour. Geophys.Res.Lett. 33, L23611.

Souza, J.M.A.C., de Boyer Montgut, C. and Le Traon, P.Y., 2011. Comparison between three implementations of automatic identification algorithms for the quantification and characterization of mesoscale eddies in the South Atlantic Ocean, Ocean Sci. Discuss., 8, 483531, doi:10.5194/osd-8-483-2011.

Swart, S., Speich, S., Ansorge, I.J., Goni, G.J., Gladyshev, S. and Lutjeharms, J.R.E., 2008. Transport and variability of the Antarctic Circumpolar Current South of Africa. J. Geophys.Res. 113, C09014.

The Drakkar Group, 2007: Eddy-permitting ocean circulation hindcasts of past decades. CLIVAR Exchanges, Vol. 12, International CLIVAR Project Office, Southampton, United Kingdom, 814. 
Thompson, S.R., Stevens, D.P. and Doos, K., 1997. The importance of interocean exchange South of Africa in a numerical model. J.Geophys.Res. 102, 33033315.

Treguier, A.M., Boebel, O., Barnier, C. and Madec, G., 2003. Agulhas eddy fluxes in a 1/63 ${ }^{\circ}$ Atlantic model. Deep-SeaRes. II50, 251280.

Treguier, A.M., 1992. Kinetic energy analysis of an eddy resolving, primitive equation North Atlantic model. J. Geophys. Res., 97 (C1), 687701.

van Aken, H.M., van Veldhoven, A.K., Veth, C., de Ruijter, W.P.M., van Leeuwen, P.J., Drijfhout, S.S., Whittle, C.P. and Rouault, M. 2003. Observations of a young Agulhas ring, Astrid, during MARE in March 2000. Deep Sea Research Part II: Topical Studies in Oceanography, 50, (1), 167-195. (doi:10.1016/S0967-0645(02)00383-1).

van Sebille, E., Biastoch, A., van Leeuwin, P. and deRuijter, W., 2009. A weaker Agulhas Current leads to more Agulhas leakage. Geophys. Res. Lett., 36, L03601, doi:10.1029/2008GL036614.

van Sebille, E., Beal, L., and Biastoch, A., 2010a. Sea surface slope as a proxy for Agulhas Current strength. Geophys. Res. Lett., 37, L09610, doi:10.1029/2010GL042847.

van Sebille, E., van Leeuwin, P., Biastoch, A. and de Ruijter, W., 2010b. Flux comparison of Eulerian and Lagrangian estimates of Agulhas leakage: A case study using a numerical model. Deep-Sea Res. I, 57, 319327, doi:10.1016/j.dsr.2009.12.006.

Weijer, W., de Ruijter, W. and Dijkstra, H.A., 2001. Stability of the Atlantic overturning circulation: Competition between Bering Strait freshwater flux and Agulhas heat and salt sources, J. Phys. Oceanogr., 31, 23852402.

Weijer, W., de Ruijter, W., Dijkstra, H.A., and van Leeuwen, P.J., 1999. Impact of interbasin exchange on the Atlantic overturning circulation, J. Phys. Oceanogr., 29, 22662284 .

Whitworth III, T. and Nowlin, W.D., 1987. Water masses and currents of the Southern Ocean at the Greenwich Meridian. Journal of Geophysical Research. 92 (C6), 64626476. 